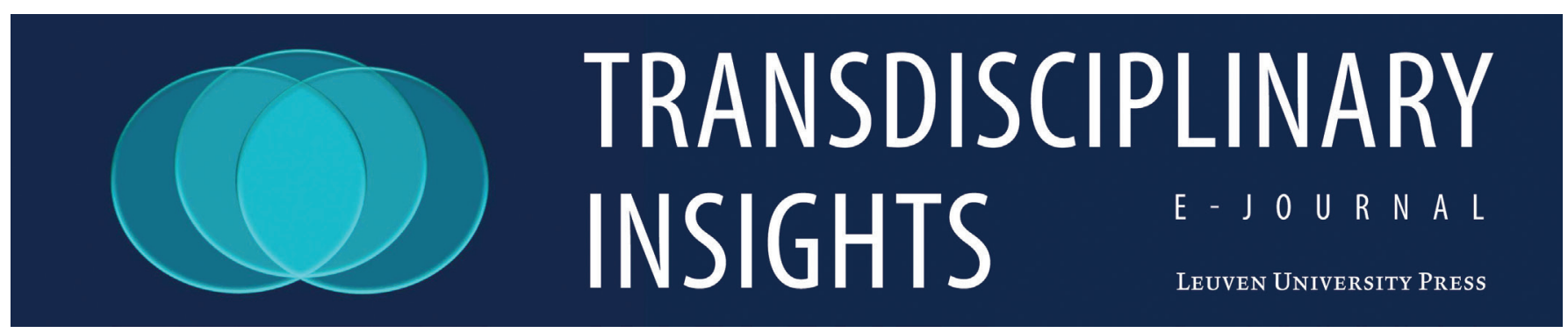

\title{
Down to Counsel: Towards A Transdisciplinary Toolbox for Non-directive Counseling in Prenatal Screening for Down Syndrome
}

\author{
Laura Costan, Matthew J. Devine, Maud van Dinther, Louise Hendrickx, Job Meijer, Nynke van \\ Uffelen, Eline Zenner
}

\begin{abstract}
Since the introduction of non-invasive prenatal testing (NIPT) in Belgium in 2013, expectant parents have had access to a new efficient and reliable test for genetic abnormalities, including trisomy 13, 18 and 21. In 2017, the Belgian government decided to cover over $95 \%$ of the cost for all women who choose to take this test. In this context, a diagnosis of trisomy 21 (Down syndrome) presents an especially challenging decision for parents: it is impossible to tell the severity of impairment prenatally, and although several medical risks are involved in the condition, many individuals with Down syndrome live a long, happy, and relatively independent life (Shakespeare, 1998; Scott et. al., 2014). Expectant parents face a very difficult situation: how to decide whether or not to terminate a pregnancy? It appears that termination is becoming the routinized outcome of the clinical encounter during which a diagnosis is delivered.

The intricacy of the matter, and the fact that many actors are involved, lead to the necessity of a transdisciplinary methodology when scrutinizing the future of prenatal counseling. However, medical professionals tend to approach Down syndrome from an exclusively medical perspective (Skirton and Barr, 2010), leaving aside the economic, social and psychological dimensions of living with Down syndrome. This may result in unbalanced information; some (perhaps precipitously) refer to this phenomenon as 'nudging practices' (Hippman et. al., 2012; Reid et. al., 2009). In order to address this imbalance, we adopt a stakeholder approach in this project: we consulted experts with diverse backgrounds and fields of expertise. Through this transdisciplinary approach, we hope to bring about a more transdisciplinary perspective directly within the offices of gynecologists and GPs. More specifically, we aim to find ways to provide GPs and gynecologists with direct access to information about the aforementioned dimensions of Down syndrome.

The next step is to define a strategy to achieve this goal. Given the fact that medical professionals often lack both time and easy access to concise information about Down syndrome to present a nuanced perspective (Ahmed et. al., 2007), but are still the first in the prenatal screening process, the output of this project is the idea of an online tool in a succinct Q\&A format. The goal of such a website would be to provide up-to-date, easily accessible and balanced
\end{abstract}


information for general practitioners and gynecologists on multiple aspects of Down syndrome. This way, in anticipation of and directing explicitly towards further counseling by a multidisciplinary team, physicians can provide expectant parents with a more balanced, transdisciplinary view of Down syndrome, thereby enhancing their capability to make informed, autonomous and hence sustainable decisions about their pregnancies.

\section{Key words}

Prenatal screening, Down syndrome, non-directive counseling, non-invasive testing, informed decision making. 


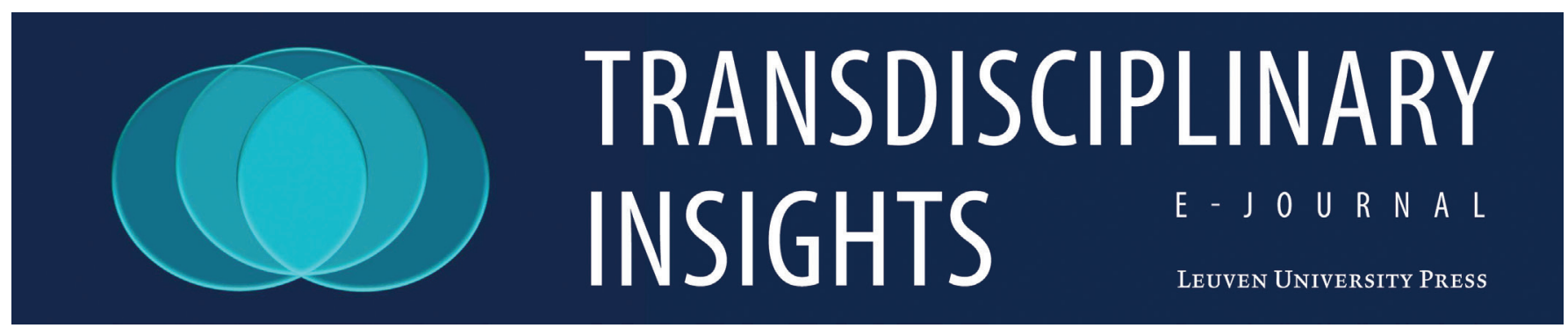

\section{Down to Counsel: Towards A Transdisciplinary Toolbox for Non-directive Counseling in Prenatal Screening for Down Syndrome}

\section{Laura Costan, ${ }^{1,2}$ Matthew J. Devine, ${ }^{1,3}$ Maud van Dinther, ${ }^{1,4}$ Louise Hendrickx, ${ }^{1,5 \cdot}$ Job Meijer ${ }^{1,6 \bullet}$, Nynke van Uffelen, ${ }^{1,7 \bullet}$ \\ Eline Zenner ${ }^{1,8^{*}}$}

$1 \mathrm{KU}$ Leuven - University of Leuven, Honours Programme Transdisciplinary Insights, Leuven, Belgium;

$2 \mathrm{KU}$ Leuven - University of Leuven, Master student European Studies, Leuven, Belgium;

3 KU Leuven - University of Leuven, Research Master student Philosophy, Leuven, Belgium;

$4 \mathrm{KU}$ Leuven - University of Leuven, Master student Medicine, Leuven, Belgium;

5 KU Leuven - University of Leuven, Master student Drug Development, Leuven, Belgium;

$6 \mathrm{KU}$ Leuven - University of Leuven, Master student Philosophy, Leuven, Belgium;

7 KU Leuven - University of Leuven, Master student Philosophy, Leuven, Belgium;

8 KU Leuven - University of Leuven, Faculty of Arts, Quantitative Lexicology and Variational Linguistics (QLVL) Unit, Brussels, Belgium;

*These authors contributed equally to the work.

\$Email: Eline.Zenner@kuleuven.be

\section{Challenge Statement}

Strategies for non-directive counseling in prenatal screening for Down syndrome

\section{Introduction}

In the past decades, prenatal screening and reproductive technology have advanced rapidly. One of the latest and most widespread of these innovations is the non-invasive prenatal test (NIPT). In the past, prenatal screening for fetal abnormalities was performed by a non-invasive combination test, which consisted of an ultrasound scan measuring the nuchal translucency and a blood test of the mother resulting in an odds ratio for chromosomal disorders. This would be followed by an invasive (and hence not risk-free) amniocentesis or chorion villus biopsy in case of a probability ratio of more than 1 out of 300 or 500 for disorders. Like the combination test, the new NIPT holds no risk of harming the fetus (Allyse et al. 2015), as it allows fetal trisomies to be detected through a blood test. However, it is at the same time notably more accurate: it delivers a binary outcome (positive/negative result) instead of an odds ratio. Additionally, the NIPT can be conducted at an earlier time in the pregnancy than the more reliable amniocentesis (Lewis et al. 2014). A positive NIPT is, however, not $100 \%$ conclusive, so it is still advised to conduct an amniocentesis after a positive screening result, although this advice is not always taken to heart (Chetty et al. 2013).

Because of the advantages of the NIPT, in 2017 Belgian Federal health minister Maggie De Block made the decision to reimburse almost the whole cost of it to every 
Belgian pregnant woman. This results in many pregnant parents facing difficult decisions, namely whether to screen or not and what to do after receiving a positive NIPT result. We choose to focus on Down syndrome in this project because, in the case of trisomy 21 , the dilemma whether to terminate a pregnancy or not has an added complexity. There are three main reasons for this. Firstly, the chromosomal defect has the highest prevalence and visibility of the three trisomies that are detected with the NIPT. Therefore, prenatal screening for Down syndrome will reveal the condition itself; however, it will not reveal the severity of the associated impairment. Odds ratios on medical risks provide odds, not certainty. This is in contrast to the other conditions screened for with the NIPT, trisomy 13 or 18 (see Savva et al. 2010, 61), which are non-viable conditions. The multi-varied ways in which Down syndrome may manifest can only be known after birth and throughout the lifespan; termination therefore implies a life-long uncertainty and a lingering 'what if'. Secondly, most people with trisomy 21 can live a long and relatively care-free life (again, in contrast to people with trisomy 13 or 18 , see Savva et al. $2010,61)$, which increases the difficulty of the choice. Thirdly, society seems to have evolved to a point where termination has become an expected outcome of the decision-making process. These three points emphasize the importance of counseling in order to stimulate wellinformed, autonomous decision-making. However, out of the annual 15-million-euro budget provided for the reimbursement of the NIPT, no funding has been made available for (multidisciplinary) counseling (De Block, 2017).

Despite the focus on Down syndrome, this project has a broader relevance: the need for thinking about autonomous decision-making grows as technology and science progress (Allyse 2015). Given these considerations, this project focuses on the following question: how can non-directive counseling be stimulated within the current Belgian healthcare structure to ensure free, well-informed decisions by parents concerning prenatal screening for Down syndrome?

\section{Focal point}

To tackle this question, we began by examining it closely in order to choose a focal point. As a first step, we scrutinized the original challenge as described by Eline Zenner (cf. supplement 1), which contained several assumptions that were in need of further research. A preliminary analysis (cf. supplement 2) showed that there were indeed important ethical questions at stake about the relationship between disability and society at large. At the same time, it would be naïve to try to free pregnant parents of all 'nudging' influences that stem from society's perspectives on Down syndrome. Instead, we began by following an actor constellation game. As part of a transdisciplinary research approach, the purpose of this activity is to examine all the potential actors or stakeholders involved in such a challenge (e.g. individuals with Down Syndrome, parents, siblings, medical professionals, therapists, etcetera), think about how these actors are all involved, and thereby determine where our contribution could be most impactful, yet realistic (see supplement 11, and https://naturalsciences. ch/topics/co-producing_knowledge/methods/actor_ constellation_final).

We directed the focus of this project on GPs and gynecologists. This move was motivated by the following considerations. Firstly, nowadays the NIPT is often offered as a 'routine part' of the prenatal care system; screening is often a taken for granted practice, rather than a subject of free choice (Birko et al. 2018, 5). It is important that medical professionals such as GPs and gynecologists are aware of the potential benefits and drawbacks of offering parents the conscious choice of whether or not to screen in the first place.

Secondly, GPs and gynecologists are often the first to deliver the NIPT-results to their patients. Although counseling is available through channels like genetic centers connected to the Flemish university hospitals and NGOs such as Fara, it is typically offered to parents only after they receive the positive NIPT-result or when they explicitly seek advice. The way in which a medical professional presents a choice can influence the patient's decision-making process (see for instance Gorin et al., 2017 for a definition and ethical use of 'nudging'). Therefore, health-care professionals play a crucial role in the guidance of the decision-making process (Korenkomp et al., 2006). In other words: first impressions matter. It should, however, be added that nudging is not always or even most of the time an intentional practice of medical professionals, and we recognize that many medical professionals do support informed decision-making and a non-directive approach to counseling, but we still believe there is opportunity for improvement.

Thirdly, given their educational background, GPs and gynecologists often merely have a medical perspective 
on the matter. Therefore, they are inclined to focus on the medical aspects (and therefore mainly on the medical risks) of the condition, leaving out other substantial practical and emotional consequences of living with a child with Down syndrome. A one-sided perspective on the subject may (unintentionally) entail the danger of nudging, and this puts the autonomy of the patient(s) in question.

From these findings, we concluded that GPs and gynecologists are the authoritative and common factor in nearly every pregnancy, which makes them the most effective disseminators of information from diverse perspectives. As such, we see an opportunity to enrich these central actors with a transdisciplinary perspective. What is distinctive about a transdisciplinary approach is that it not only endeavors to work between several disciplines. It aims to work beyond these disciplines, involving academics from relevant disciplines, but also non-academic stakeholders with different but nonetheless crucial expertise (Choi et al. 2006, 356). Our hypothesis is that, when GPs and gynecologists embrace a broader view than the medical perspective alone (viz. providing more information on the condition than the purely medical one), the first crucial contact with their patients will be more nuanced and will stimulate free decision-making and/or seeking further, more transdisciplinary counseling - in the proper sense of the word - will be encouraged (see Hippman et al. 2012, who consider 'balanced' descriptions impossible, but instead strive for nonjudgmental terminologies, helping families evaluate possibilities in the context of 'their own values, coping strategies and support networks').

We acknowledge, however, that GPs and gynecologists often lack the time for in-depth counseling (Williams et al. 2002, 233; Sup 10). It therefore remains important to refer patients to the existing (transdisciplinary) institutes for counseling. A solution to the initial challenge must take these time constraints into account.

We propose the creation of an online tool, developed for GPs and gynecologists, where they can quickly find reliable and up-to-date information on prenatal screening, decision-making and living with Down syndrome. This information will be transdisciplinary: it will cover not only medical aspects, but also social implications, psychological dimensions, financial arrangements, education opportunities and so on. At the moment, no such tool is available in Belgium; tools for non-directive counseling do exist (see for example Reid et al., 2009 and Fransen et al., 2009 for research on these topics, and see Ahmed et al., 2007 for a description of the tool AnSwer, developed by Tom Shakespeare), but they are not specifically adjusted to the Belgian context. Our tool is not confined to counseling alone; it aims for an overview of multiple perspectives, including for example educational opportunities and relevant labor or financial laws on Down syndrome. Once finished, we suspect that this tool will broaden the perspectives of medical professionals and therefore enhance their use, understanding of and referral to non-directive counseling, and we hope that it will ensure that non-directiveness is supported within the initial clinical encounter.

\section{Stakeholder Approach}

The next step is to decide on the shape and content of such a tool. The aim is to bring about a broader, more transdisciplinary view, and a transdisciplinary tool must be created in a transdisciplinary manner. The complexity of the challenge implies that many different actors are involved: there are many possible perspectives on Down syndrome. Therefore, we chose a stakeholderapproach. All related actors must be consulted in order to demarcate what they think is relevant content for the purpose of the tool, and to discern whether the basic idea of the tool is useful in the first place.

The selection of stakeholders from the initial list included in the challenge proposal (see supplement 1) was made based on considerations concerning the relevance of the subject field(s) and the variety of different perspectives within the whole selection: interviews were held with people with medical, social, and individual stakes in the different dimensions touched upon by prenatal screening, including the general impact on society, prenatal counseling, and life with Down syndrome. These meetings provided us with valuable insights that helped us to define the content, outline and design of our proposition. The selection of who to meet was based on availability, accessibility, and ensuring a diversity of perspectives (e.g. academic, professional, lived-experience experts).

Firstly, via the organization Downsyndroom Vlaanderen, we met with several people with Down syndrome and their family members (cf. supplement $4,7,8$ ). This provided valuable information about everyday life with Down syndrome. For example, it became clear that 
experiences are extremely variable; it is impossible to provide a single, unified picture of what life is like with Down syndrome, which may complicate prenatal counseling. Moreover, by talking to parents we acquired valuable insights on experiences with the (current) medical system and counseling practices during and after the pregnancy. Numerous parents felt the necessity for better counseling, more information and a better referral process to institutions or organizations for counseling. These parents felt like they were on their own after receiving the diagnosis; they had to look for information and counseling by themselves, and some felt they needed to defend their decision to keep their child with Down syndrome during every interaction with medical professionals.

Secondly, we spoke with Jean Jacques Cassiman, professor of genetics at the KU Leuven (cf. supplement 9). The genetic perspective is vital because genetic centers are the prime location for innovations in genetic research and these centers strongly adhere to neutral counseling. Cassiman argued that, even though science defines the possible, society demarcates the boundaries of the acceptable. In his opinion, prenatal screening is progress. The NIPT is more and more becoming standard practice in the daily organization of peripheral hospitals; this could pose problems since there are no extra funds made available for the necessary counseling to counterbalance this push. It is far from unthinkable that our future is one where termination is the standard (or even obliged) outcome of positive NIP-tests.

Thirdly, we met with Fara, a nonprofit pregnancycounseling organization that operates in Belgium (cf. supplement 5). Fara endorses the model of nonjudgemental counseling and shared decisionmaking; they believe care providers have a responsibility to stimulate the parents to make conscious, wellconsidered choices. Fara's insights on counseling are of great value for our project. For example, they note that medical professionals sometimes tend to see Down syndrome as a 'problem' or something negative. Doctors screen for disabilities, while parents screen for assurance that their baby is healthy: however, a negative attitude could be contested in cases where a fetus is diagnosed with Down syndrome. Another important insight concerns the importance of anxiety and fear of the unknown. A diagnosis often goes hand in hand with odds ratios; it must be taken into account that people tend to count on the worst-case scenario.
Fara stressed the factor of uncertainty: one will only know the reality when one chooses to keep the child, however hard it may be. When one chooses to terminate, a life-long 'what if' lingers. Lastly, Fara stipulated that the medical professional does not need to know what the best solution is for the patient, simply because he/she cannot know what it is. Counseling should not start with an answer set in stone.

Fourthly, we spoke with a member of Cozapo, a parent-to-parent organization that seeks to help alleviate the psychological repercussions suffered by those who terminate their pregnancies. The perspective of women who decided to terminate is indispensable. Firstly, the importance of consciousness of the 'life-long what if' was stressed again as a major consequence of terminating a pregnancy. Another important insight was that parents should be informed not only of the consequences of keeping the child, but also of the exact procedure that would be followed after they chose to terminate, since this is a very vulnerable time for parents.

Fifthly, genetic screening goes hand in hand with numerous ethical questions. This is why we chose to speak with Kasper Raus, bioethicist at the university hospital of Ghent (cf. supplement 6). Raus pointed to the fact that attention must be paid to the way information is conveyed. For example, an $80 \%$ chance of living has a different connotation than a $20 \%$ chance of dying. Also, he made us aware of the fact that there is no unified framework to facilitate counseling in Belgium, meaning that certain information might not reach prospective parents because it is assumed to have already been provided to them by other healthcare professionals (where this is not necessarily the case).

Lastly, we met with Luc De Catte, gynecologist and professor at the KU Leuven (cf. supplement 10). Meeting the target group itself is essential, because it gives them (in this case, the gynecologists) the opportunity to co-create the content of the tool. This increases its quality and the odds that it might actually be used in practice. Also, this meeting gave important insights into how to tackle the more strategic questions linked to this project: what is the best way to enrich medical professionals with transdisciplinary perspectives, and how can we convince GPs and gynecologists to use this tool? De Catte agreed that the nature of the current curriculum for medical students is too medical. However, changing the curriculum is not realistic within 
this decade; it will not be realistic for our tool to gain an official place at the university of KU Leuven just yet. Also, he emphasized the importance of concise information about nonmedical aspects of Down syndrome that medical professionals can easily and quickly consult. This will increase the odds that the tool will actually be consulted.

\section{Outline of the Online Tool}

Meeting these stakeholders affirmed the need for a transdisciplinary online tool for GPs and gynecologists. Since they are often the first ones in contact with the patients when announcing the NIPT results, they can have a huge impact. We hope that non-directiveness will be encouraged in this initial contact when these medical professionals have a more comprehensive in other words, not merely medical - perspective on Down syndrome.

As mentioned, there is a limited amount of time available for counseling and GPs and gynecologists tend to focus on the medical perspective. Therefore, to improve this crucial first interaction, these medical professionals must have easy access to concise information on Down syndrome from multiple perspectives. This is why we decided on a freely-accessible brief online course.

The tool, shaped as a Q\&A format, must contain reliable and up-to-date information from every relevant involved perspective, gathered in a transdisciplinary manner. Especially the input from the gynecologists and GPs must not be forgotten: this way, the tool is co-created by its target group, which increases its quality and the odds that it will be used in practice.

The stakeholder insights also provided the outline of the content that must be covered (cf. supplement 3). The medical perspective is not the only possible one on Down syndrome; other perspectives are relevant to the parents, for example economic, social and psychological dimensions of living with the disability. Furthermore, the perspective of people with Down syndrome must not be forgotten. An example is the following question: 'What education possibilities are there for a person with Down syndrome?' This question would link to a page with a description of the possibilities and to relevant institutions. The website idea is meant to specifically tackle the situation in Belgium, which allows for the inclusion of information regarding government aid, types of schooling, relevant laws and so on.
In addition to its own content, the website would contain referrals to websites of organizations for counseling such as Fara. It should also include a feedback form so that information can be updated, adjusted or supplemented by the actors that visit the website. Also, to ensure GPs and gynecologists would notice the website, it would be good if known websites such as the 'Vlaamse Vereniging voor Obstetrie en Gynaecologie' (VVOG) contained a link to the tool.

Through this tool, the medical professional becomes aware of the fact that Down syndrome is more than a medical condition and an odds ratio; their view is broadened, which leads to a more nuanced perspective from which parents are informed about their prenatal testing results. We understand that we cannot expect physicians to counsel in the full sense of the word, but they can still ensure that all options are kept open to their clients, and this is more likely when other perspectives are taken into account. At the same time, the tool can help as a guide through counseling; it provides answers to parents' questions and contains a list of relevant institutions to refer them to.

\section{Conclusions and Limitations}

This website, as a last remark, would neither be a panacea for the general issues surrounding genetic screening, nor does it suggest to be exhaustive of all steps that could contribute to informed decision-making in the case of prenatal screening. Regarding genetic screening generally, it is paramount that further research is conducted into the role that disabilities play in society, effective ways of integrating ethical practice into medicine as technology opens up new possibilities, and the practice of counseling itself. However, this website may set some precedent for counseling, and in that sense provide a baseline within medical practice to deal with the changing landscape of what childbirth is in society. Lastly, more research into the impact of the NIPT within Belgium is necessary.

Regarding informed decision-making, some further limitations of this project should be noted. After all, a fully transdisciplinary approach to prenatal screening would endorse collaboration from multiple experts as much as possible. This was our intention in collaborating with multiple academic, professional, and livedexperience experts. It may be argued that our decision to focus on physicians deviates from this collaboration. By focusing on physicians, we do not intend to narrow 
transdisciplinarity to one single actor. As mentioned in the paper, since prenatal screening is a process that begins within the medical sphere, physicians are the first point of contact for parents. The presence of such a website, for instance, could encourage the likelihood that news is delivered in a sensitive manner, without the use of derogatory language or language expressing pity, a conclusion of several studies that sought to understand the preferences of mothers in receiving news about a diagnosis of Down syndrome. (See Skotko et al., 2009). We nonetheless endorse physicians making appropriate referrals to organizations better equipped to provide fuller counseling. Indeed, we believe enriching physicians' awareness of the multi-dimensionality of Down syndrome will not only allow them to answer initial questions parents may have (for example during the delivery of the news), but also encourage them to make appropriate referrals to said organizations. Providing physicians with basic knowledge of other dimensions of Down syndrome is not intended to replace the role of other counseling resources.

In any case, our proof of concept might be a first step towards an approach to enriching medical professionals with a broader, more comprehensive view on the matter. GPs and gynecologists tend to have a medical perspective on Down syndrome, and they often lack the time to do in-depth counseling after parents receive a positive NIPT-result. We argue for the usefulness of an online tool in a succinct Q\&A format that provides reliable, up-to-date information on Down syndrome from multiple perspectives. A broader, more comprehensive view will lead to more nuanced counseling. The importance of transdisciplinarity in complex matters such as this one cannot be underestimated; therefore, the tool must be created in a transdisciplinary manner so that the outcome will be of the same nature. Through this tool, physicians can provide expectant parents with a more balanced, transdisciplinary view of Down syndrome, thereby enhancing their capability to make informed and autonomous decisions about their pregnancies. We hope that this project will be fully executed in the future and that it will successfully be put into practice.

\section{Supplementary Materials}

1. The original challenge document

2. Assumptions in the original challenge
3. Website table of content

4. Video fragment 1

5. Video fragment 2

6. Video fragment 3

7. Video fragment 4

8. Video fragment 5

9. Audio fragment 1

10. Audio fragment 2

11. Actor constellation game

12. 'Facing the Future' symposium presentation

\section{References}

Ahmed S, Bryant L, and Hewison J. 'Balance' Is in the Eye of the Beholder: Providing Information to Support Informed Choices in Antenatal Screening via Antenatal Screening Web Resource. Health Expectations. 2007 Dec; 10(4): 309-320. https://doi. org/10.1111/j.1369-7625.2007.00455.x.

Allyse M., Minear A. et al., Non-invasive prenatal testing: a review of international implementation and challenges, Int J Womens Health. 2015; 7: 113-126

Birko, Stanislav, Marie-Eve Lemoine, Minh Thu Nguyen, Vardit Ravitsky. Moving Towards Routine NonInvasive Prenatal Testing (NIPT): Challenges Related to Women's Autonomy. OBM Genetics 2018

Chetty S., Garabedian M. J. and Norton M. E. (2013), Uptake of noninvasive prenatal testing (NIPT) in women following positive aneuploidy screening. Prenat Diagn, 33: 542-546.

Choi, B.C K., Pak, A.W.P. Multidisciplinarity, interdisciplinarity and transdisciplinarity in health research, services, education and policy: 1. Definitions, objectives, and evidence of effectiveness. Clinical Investigative Medicine. 2006; 29(6): 351-364.

De Block, Maggie, De Block betaalt NIP-test naar downsyndroom terug aan alle zwangere vrouwen die de test wensen, 29 May 2017, available at: http://www. deblock.belgium.be/nl/maggie-de-block-betaalt-niptest-naar- downsyndroom-terug-aan-alle-zwangerevrouwen-die-de-test, accessed on June 8, 2018

Fransen Mirjan P., Wildschut Hajo, Vogel Ineke, Mackenbach Johan, Steegers Eric and Essink-Bot Marie-Louise, Information about prenatal screening for Down syndrome: Ethnic differences in knowledge. Patient Education and Counseling. 2009; 7(2): 279-288.

Hill M, Barrett A, Choolani M, Lewis C, Fisher J, Chitty LS. Has noninvasive prenatal testing impacted termination of pregnancy and live birth rates of infants with Down syndrome? Prenatal Diagnosis. 2017; 37(13): 1281-1290. doi:10.1002/pd.5182.

Hippman C, Inglis A, Austin J. What Is a 'Balanced' 
Description? Insight from Parents of Individuals with Down Syndrome. Journal of Genetic Counseling. 2012 Feb; 21(1): 35-44. https://doi.org/10.1007/ s10897-011-9417-2.

Korenromp MJ, Page-Christiaens GCML, van den Bout J, Mulder EJH, Visser GHA. Maternal decision to terminate pregnancy in case of Down syndrome. Am J Obstet Gynecol 2007

Korenromp MJ, Page-Christiaens GC, van den Bout J, et al. Is there pressure from society to terminate pregnancy in case of a fetal anomaly? Prenat Diagn 2006; 26: 85-86.

Lewis C., Hill M. et al., Non-invasive prenatal testing for trisomy 21: a cross-sectional survey of service users' views and likely uptake, BJOG 17 January 2014, 582.

Maxwell S., Bower C., and O'Leary P. (2015) Impact of prenatal screening and diagnostic testing on trends in Down syndrome births and terminations in Western Australia 1980 to 2013. Prenat Diagn, 35: 1324-1330.

Neyt M, Hulstaert F, Gyselaers W, Introducing the noninvasive prenatal test for trisomy 21 in Belgium: a cost-consequences analysis, BMJ Open 2014.

Reid B, Sinclair M, Barr O, Dobbs F, Crealey G. A MetaSynthesis of Pregnant Women's Decision-Making Processes with Regard to Antenatal Screening for Down Syndrome. Social Science \& Medicine. 2009 Dec; 69(11): 1561-1573. https://doi.org/10.1016/j. socscimed.2009.09.006.

Savva, G. M., Walker, K. and Morris, J. K. (2010), The maternal age-specific live birth prevalence of trisomies 13 and 18 compared to trisomy 21 (Down syndrome). Prenat. Diagn., 30: 57-64.

Scott M, Foley K R, Bourke J, Leonard H, and Girdler S. 'I Have a Good Life': The Meaning of Well-Being from the
Perspective of Young Adults with Down Syndrome. Disability and Rehabilitation. 2014 July; 36(15): 12901298. https://doi.org/10.3109/09638288.2013.854843.

Shakespeare T. Choices and Rights: Eugenics, Genetics and Disability Equality. Disability \& Society. 1998 Nov; 13(5): 665-681. https://doi.org/10.1080/09687599826452.

Skirton $\mathrm{H}$, Barr O. Antenatal screening and informed choice: a cross-sectional survey of parents and professionals. Midwifery. 2010 Dec; 26(6): 596-602. doi:10.1016/j.midw.2009.01.002

Skotko BG. Prenatally diagnosed Down syndrome: mothers who continued their pregnancies evaluate their health care providers. Am J Obstet Gynecol 2005; 192: 670-677.

Skotko G., Capone G.T. and Kishnani P.S. Postnatal Diagnosis of Down Syndrome: Synthesis of the Evidence on How Best to Deliver the News. 2009; 124(4): 751-758.

Stanislav B., Lemoine M. et al., Moving Towards Routine Non-Invasive Prenatal Testing (NIPT): Challenges Related to Women's Autonomy. OBM Genetics 2018; 2(2): 2018.

UZ Leuven, Centre for Human Genetics, NIPT, 04-022017, available at: https://www.uzleuven.be/en/ nipt\#reimbursed, accessed on June 5, 2018.

Verweij E. J., Oepkes D. and Boer M. A. (2013), Changing attitudes towards termination of pregnancy for trisomy 21 with non-invasive prenatal trisomy testing: a population- based study in Dutch pregnant women. Prenat Diagn, 33: 397-399.

Williams C., Alderson P. and Farsides B. (2002), What constitutes 'balanced information in the practitioners' portrayals of Down's syndrome? Midwifery, 18: 230-237. 


\section{Supplement 1: The Original Challenge document}

\section{ABOUT YOUR CHALLENGE}

\section{NAME OF THE CHALLENGE}

Would the world be a better place without them?

Strategies for non-directive counseling in prenatal screening for Down syndrome.

(Written by Eline Zenner on behalf of Downsyndroom Vlaanderen)

Could you please state a specific challenge, problem or question? If you have more than one challenge, please submit each challenge separately. Please be aware that if the same or a very similar challenge is submitted by multiple actors, we will pool this into a single challenge, and as a result, the challenge might diverge slightly from what you submitted.

When we look at our children, we see people. We see people with hopes and dreams, fears and desires, hands, fingers, toes, favorite food, bath time rituals, bubbles and images of the life we share. What we see as parents of a child with Down syndrome stands in sharp and bleak contrast with what society sees. Society sees a medical risk, increased odds for early-onset dementia, heart condition, visual impairment and autism spectrum disorder. Society sees a financial burden, and waiting lists for care facilities for the intellectually impaired. Society sees a syndrome that no longer needs to be. A syndrome that we can screen for.

From 2013 onwards, a new and non-invasive way of prenatally screening for Down syndrome gained ground in Belgium and abroad. The NIPT (Non-Invasive Prenatal Test) is more accurate than the traditionally used double test, it holds fewer risks for the fetus than an amnio (where a needle is guided through the abdominal wall and into the fluid sac), and can be conducted at a much earlier point in pregnancy. Without going into medical detail, the test isolates the fetus's DNA from a blood sample taken from the mother and offers a near-conclusive diagnosis (with more than $98 \%$ accuracy) for trisomy 13, trisomy 18, and trisomy 21.

On Monday, 29 May 2017 Belgian Minister of Social Affairs and Health Maggie De Block announced that 15 million euro would be made available to refund the NIPT to every Belgian pregnant woman. Belgium is currently as such the first European country to refund the test to every future parent instead of targeting parents in high-risk groups (e.g. using maternal age as decisive factor). At Downsyndroom Vlaanderen (an organization of and for parents with a child with Down syndrome) we absolutely support this initiative, as it prevents an opposition between 'medicine for the rich' (those who can afford the expensive test) and 'medicine for the poor' (those who cannot afford the test). What we however object to is that the available funding solely covers the costs of the lab test itself. Money for non-directive multidisciplinary counseling is not provided. That is what this proposal is about, with a specific focus on trisomy 21 , the chromosomal variant more commonly known as Down syndrome. ${ }^{1}$

The reason to focus on Down syndrome is three-fold. First, the NIPT is publicly often referred to as 'the Down test', as this condition has the highest prevalence and hence the highest visibility of the three trisomies. Additionally, where babies with trisomy 13 and trisomy 18 usually die in the womb or in their first year of life, most people with trisomy 21 can lead long and relatively care-free lives (with a current mean life expectancy of about sixty years). Finally, because of the higher visibility of Down syndrome, there is a more outspoken and more public debate on the NIPT and its consequences for people with this syndrome than for any other condition that can be detected prenatally. Are we heading toward a world without Down syndrome?

The answer to this question is not what we as parents of a child with Down syndrome want to focus on. If future parents make a well-informed and well-considered decision following a prenatal diagnosis of Down syndrome to 
terminate their pregnancy, then it is by no means our desire to stop them. No matter how dearly we love our children, we support a pro-choice vision on prenatal screening: every parent has the right to choose whether to terminate or to continue a pregnancy.

This one key sentence forms the cornerstone of our challenge: every parent has the right to choose.

Historically, this pro-choice vision largely served to provide a contrast with the traditional pro-life stance: abortion was illegal in most countries under all circumstances, in Belgium even until 1990. Women around the world defended (and still need to defend) their right to have a choice whether or not to continue a pregnancy, in essence defending their right to terminate. Because of this socio-political context, the decision to terminate a pregnancy is subsumed under the flag of a 'pro-choice' vision. It is however incorrect to equate a pro-choice vision with a pro-termination stance: we should be careful not to evolve to a point where, under certain conditions, allowing a woman to choose entails that we expect a woman to terminate. Under a true pro-choice approach, the choice for life and the choice for termination should at all times be measured with equal scales.

In the specific context of the NIPT, a pro-choice vision entails that future parents first and foremost make a conscious decision whether or not they want to screen for disabilities and abnormalities during pregnancy. Once they decide to screen, a second choice then is what to do with the outcome of such screenings. In this respect, society seems to be evolving to a point where screening is a given rather than a choice, and termination is the standard outcome of a positive diagnosis in prenatal screening. The parents in our network who have consciously decided to keep a child with a disability after positive results in prenatal screening find themselves faced with hostile comments and repeatedly have to defend their choice to others, including medical staff. Why bring a child into the world with a syndrome that no longer needs to be? The recent decision to refund the NIPT on a national level without mirroring this financial initiative with efforts concerning counseling further illustrates this termination-oriented climate.

As parents of a child with Down syndrome, who have joined forces in the Downsyndroom Vlaanderen voluntary association, we believe that this evolution presents an opportunity and a challenge to society. How can we provide future parents, and society at large, with the tools required to make a conscious and well-informed decision on the outcome of prenatal diagnosis without passing judgement or steering parents in specific directions? We ask this question specifically for trisomy 21 , but insist on the much broader impact of the answer. Down syndrome is one of the most traceable conditions, and hence the first to be subject to this type of large-scale prenatal screening, but it is on average definitely not the most life-shattering condition one can be faced with in terms of quality of life.

Put differently, screening for Down syndrome is merely the beginning of a general societal tendency to screen for conditions, deviations and abnormalities during or prior to pregnancy, and as such presents us with some questions we need to address today rather than tomorrow.

Would you like to add some objectives to that challenge? For example, can you imagine how you want the future to be with regard to this specific challenge? Is there any specific result that you want the research group to reach?

Babies with Down syndrome are sometimes said to be the canaries in the genetics coalmine. This vibrant metaphor is not per se nuanced, but does underline the urgency of our challenge. Non-invasive screening for Down syndrome is merely the tip of an iceberg that will in any case be revealed over the following decades. The breathtaking speed of knowledge acquisition in genetics has left our moral compass in need of recalibration. How have we, as a society of human beings, embarked on the endeavor of extensive genetic screening without equally explicitly and, more importantly, publicly addressing the question of the value of a human life and of the scales that are used in weighting this value: who decides what a meaningful life is? We need to address this issue from a transdisciplinary scientific framework, but we also and more importantly need to come up with a strategy to disseminate insights on the matter to a wide audience. 
On the broader level of genetic screening, the question is how we can (re?)introduce fair play in the public debate on prenatal decisions, how we can contribute to a correct perception of life with (a child with) a disability?

On the more specific level of screening for Down syndrome, the question is two-tiered. First, we need to find out how we can provide non-directive information on Down syndrome to all future parents. How can we make sure that up to date information on the possible impact of Down syndrome on a child's and a family's living conditions finds its way to future parents, ideally even before they decide to undergo prenatal screening? As we see that centers for human genetics typically already undertake efforts in this respect, we secondly want to question the position of GPs and gynecologists in providing this information. Which tools, data, approaches etc. can we offer medical teams to inform parents of life with a child with Down syndrome in all its respects, surpassing the traditional clinical perspective of 'medical risks attached to trisomy 21' (e.g. higher incidence of heart conditions, leukemia, autism spectrum disorders and visual \& auditory impairments). At this point, the type and manner of communication is (too?) idiosyncratically tied to individual profiles. Where some doctors take efforts to provide a nuanced and well-informed position, others cannot help but take stance in one direction or another. How can we broaden the perspective and make clear that our children are people, not risks?

Additionally, we question the role of the media in the debate. Currently, the media frequently offer broad platforms to individuals who have strong opinions on prenatal screening, but do not necessarily have any notable actual experience with people with Down syndrome. Several individuals for instance make public assessments on the 'unbearable suffering' that is tied to trisomy 21 , often relying on old and colored terminology (calling people with Down syndrome mongooltjes - a term that was abandoned by WHO in the 1960s). Although this assessment may hold for a number of people with Down syndrome, it most surely does not apply to all. Public opinion on the genetic condition is however greatly colored by such mediatized debate. Schooling and care for people with Down syndrome still (especially in the later years of life) typically adopts the form of segregation rather than of participation or inclusion: day-to-day contact with people with Down syndrome is so limited for most that they decide on screening without ever having met a person with Down syndrome: the information shared in the media (in terms of both form and content) hence is of crucial importance for future parents' perception of Down syndrome.

The issues we raise here are hard to tackle in their own right, but political and economic concerns further complicate the debate. How much is society paying for prenatal screening for Down syndrome and comparable syndromes; conversely, what is the cost of supporting families with a child with Down syndrome; and what is the relation between both? What is the social meaning of increasing expenditure for scientific research on prenatal screening whilst decreasing the budget for supporting families with a child with Down syndrome? Using a raw economy-driven formulation, what is more expensive: providing the correct type of life-long support for people with Down syndrome, or refunding the NIPT to all future parents in the presupposition that the default choice following a positive diagnosis is termination (and hence not having to foot the bill as society)? What are the risks of valuing lives with such purely economic scales, also for people who do not have an extra copy of their 21st chromosome?

Several objectives can be derived from this overview. From our perspective as parents, we would like to prioritize the most practical ones:

- How can we provide future parents with non-directive information on all aspects of life with a child with Down syndrome as an a priori for prenatal screening? Downsyndroom Vlaanderen would be thrilled with a tool (a script for a video that might go viral, for instance) that allows doctors to communicate about prenatal screening and decision processes to young parents, ideally tailored to the NIPT and Down syndrome.

- How can we provide medical teams with strategies for counseling: how can we provide medical teams with specific strategies to counsel future parents on the topic of prenatal screening, ensuring that screening is provided from a multidisciplinary perspective? Downsyndroom Vlaanderen would be very grateful for a concrete proposal for a training session for doctors (GPs, gynecologists etc.) on (i) current living standards and possibilities of life with Down syndrome; (ii) existing organizations that can be addressed for instance in non-directive communication.

- How can we sensitize society at large concerning the ideologically colored and relatively outdated discourse on people with disabilities in general and people with Down syndrome in particular? 
In the next section of this proposal, we sketch precisely how this challenge could be addressed by a properly transdisciplinary team.

Could you please let us know the context of the challenge and why you think this challenge is relevant to a transdisciplinary research team? Please be aware that our transdisciplinary research teams accept only challenges that have to be dealt with from different points of view.

Below, we present some specific perspectives and questions related to the challenge. We do this for each of the KU Leuven faculties that, in our opinion, can add interesting insights. Of course, not all of these perspectives need to be addressed. Likewise, other initiatives and points of view are more than welcome.

Philosophy:

- the ethics of genetic screening;

- a cultural-historical analysis of 'normality';

- the position of uncertainty opposed to the desire for control and perfection;

- the consequences of agency in ethics ('you chose this child, so you deal with it').

Medicine:

- opposing genetic progress against ethical progress;

- critical analyses of medical training: is it more advisable to opt for in-depth experience with people who live with the disabilities that you screen for;

- counseling and prenatal diagnosis: from GPs over gynecologists to centers of human genetics;

- how will care for people with disabilities improve in the future, and how could that influence the decision making?

Arts \& Social Sciences:

- in-depth analysis of current public discourse and medical counseling;

- lexical variation and ideology: revealing connotations and stigmatization attached to

- mongooltje (vis-à-vis een baby met downsyndroom);

- communication on disabilities in a general societal context: how to ensure that people acquire a realistic perspective on the potential of people with a disability;

- communication in the prenatal context: how to convey information on people with a disability at a point in time (early pregnancy) when potential future parents are not particularly open to this type of information;

- intercultural communication: how to provide information to people with different cultural backgrounds;

- cultural history: the background to the pro-life vs. pro-choice debate, complemented with an analysis of the reasons for abortion (psychosocial reasons, medical reasons, ...), and how we can use these insights for the future. What is the distinction between these reasons and how can we tease them apart?

\section{Economic Sciences:}

- economic factors in prenatal screening and prenatal counseling;

- the 'value' of life;

- 'something's gotta give': what are we losing by spending 15 million euros on refunding the NIPT? What are we gaining?

Law:

- human rights at play in prenatal screening (see the UN Convention on the Rights of Persons with Disabilities);

- linking counseling and refunding of prenatal screening in the Belgian system: prevention is located at the regional level, but healthcare is organized on a federal level. 


\section{LUCA (Associatie KU Leuven):}

- people with Down syndrome often have great artistic abilities: what is the value of this for society?

- Psychology \& Pedagogy:

- psychological factors involved in the process of making life-changing choices;

- psychological factors of normality and differences;

- living with a family member with Down syndrome;

- sharing skills and insights in teaching about disabilities;

- the evolution in models of thinking about disabilities (from medical to social model);

- what does the future have in store in terms of teaching (M-decreet?) and training (see stakeholder Konekt's efforts) people with Down syndrome, where are we in the scale from exclusion over segregation via participation to proper inclusion?

Science:

- make predictions on the future of science and the impact on the quality of life for people with Down syndrome;

- make predictions on how expected innovations in technology can help people with disabilities gain independence, social networks, etc. (see e.g. Spotter, a GPS tracker for tracking children);

- After reading this proposal, it should be clear that the societal impact of addressing our challenge is significant. Current advances in prenatal screening have put society at a turning point. This challenge is all about the question which way to tip, and how we can provide a nudge in the preferred direction, ensuring that parents can truly hold on to their right to choose. As such, in addressing the issue of counseling for prenatal screening for Down syndrome, we hope to pave the way for similar strategies for other prenatal tests, now and in the future. It is crucial to appreciate that this proposal sees the issue of counseling in prenatal screening for Down syndrome as a first case study for a broader societal challenge. Society is evolving to a point where parents are advised to test as much as possible in advance. How can we offer parents the correct tools to deal with these tests and the information they provide?

Possible partners, experts and/or other stakeholders to involve in this challenge If you want your challenge to be dealt with not only by a transdisciplinary research group but also by stakeholders, could you please suggest stakeholders' name(s) to get involved in this research and if you have them, some contact details of each one?

In this section, we present a list of ten potential stakeholders, nine of whom have already agreed to function as stakeholders in the project. Some more information is provided on the organizations and on their position with respect to this proposal. Although we believe that this list will go a long way, other national and international stakeholders can of course be thought of.

Downsyndroom Vlaanderen vzw: Needless to say, our own organization is a stakeholder for this project. We deeply care for the topic, as we are afraid to see society evolve to a point where only traditional interpretations of perfection are welcome. More information on the position of Downsyndroom Vlaanderen in this debate can be found via this link, which also contains an overview of the national media's attention for the topic in light of the decision of Minister Maggie De Block to refund the test. Downsyndroom Vlaanderen can be found on www.downsyndroom.eu. Our organization can be contacted by e-mailing eline.zenner@gmail.com and jurgen@downsyndroom.eu.

CMEs: The centers for human genetics (Centra voor Menselijke Erfelijkheid, CME) of the university hospitals in Flanders and Brussels are natural stakeholders in this project: they are the prime location for innovations in genetic research and at the same time have always strongly adhered to neutral counseling. The CMEs are on 
board as stakeholders, though they wish to underline their own neutrality in the matter. Professor Bert Callewaert from UGent phrases the position of CME UZ Gent as follow: 'non-directive counseling has always been one of the basic guiding principles of the CME's. We however need to acknowledge that once a screening test becomes "standard and refundable", it soon finds its way to peripheral hospitals. The current criteria for refunding the NIPT are not connected to any requirements concerning counseling. This means that there is a significant risk that this crucial component of prenatal screening runs the risk of being backbenched in daily organization.' The different CMEs can be contacted as follows: bert.callewaert@ugent.be (UZ Gent), griet.vanbuggenhout@uzleuven. be (UZ Leuven), maryse.bonduelle@uzbrussel.be (UZ Brussel), geert.mortier@uza.be (UZ Antwerpen). Please note that the Pediatrics Department of UZ Antwerpen (contact stijn.verhulst@uza.be) is also interested in being involved in this project. Also marek.wojciechowski@telenet.be from UZA can be contacted as a specialist in Down syndrome.

VVOG: We have also contacted the Flemish organization of gynecologists and obstetricians (Vlaamse Vereniging voor Gynaecologie en Obstetrie, VVOG). Although a number of gynecologists are very aware of their role as counselors in the process of prenatal counseling, others take a rather clinical perspective on the matter. This way, the possibility of providing true non-directive counseling has sometimes already been closed off by the time parents arrive at CMEs for advanced testing. Hence, it is crucial to include VVOG as stakeholder in this project. The organization agrees to operate as stakeholder for the project. VVOG can be contacted by e-mailing doctor Van Keirsbilck via joachimvankeirsbilck@hotmail.com.

Kind \& Gezin: Kind en Gezin, together with its partners, aims to create as many opportunities as possible for every child, regardless of where he or she was born or where and how he or she is growing up. Kind en Gezin (Child and Family) is an agency that works actively in the "Public Health, Welfare and Family' policy area. This Flemish agency focuses on preventive treatment and guidance of young children geared to good outcomes in the future. Kind en Gezin describes its role as follows: 'We work hard to enable children to achieve their full developmental potential, physically, mentally, emotionally and socially, with respect for diversity and children's rights. This principle holds for all the different areas that we work in. Kind en Gezin is responsible for registration of high quality child care, optimal support for parents-to-be and parents with young children and the criteria that adoption agencies have to meet. We closely monitor all changes in society as a matter of course. Day in day out we come into contact with thousands of families and work with partners and other actors in the field. This gives us a wealth of information, allowing us to respond proactively and at the most appropriate time. We develop scientific methods, in both educational and medical fields, to assist us in our work. We constantly adapt our services, so that we can offer every parent and every child the best help possible. We also participate in national and international campaigns and projects: with boundless respect for every child and for the rights of the child. Child and Family wants to support parents by objective and nuanced information on prenatal screening on behalf of making an informed choice. Hereby we refer parents to several organizations with expertise in pregnancy choices, prenatal screening and diagnostics. After birth, Child and Family offers family-based support. Our services can therefore be different for each family. If there are any questions or difficulties we can't support, we provide the necessary information about who can and refer to another service or organization. If wanted, the family can further count on us. More information on Child and Family can be found on www.kindengezin.be. Kind en Gezin can be contacted by e-mailing evelyne.deguffroy@kindengezin.be'.

Fara vzw: Fara is an organization that informs and counsels about pregnancy-related choices. Fara has described its own position as a stakeholder in this project as follows: 'Fara regularly comes into contact with issues regarding prenatal testing/diagnosis. In our work, we have always put forward the model of non-judgment counseling and shared decision-making, both internally (in the work we do with clients) and externally (in our training of professionals). We emphasize the responsibility of the care providers to support parents as best as possible in making a conscious, well-considered choice they can (continue to) live with. It is our experience that parents are often not concerned with the social impact of their individual choice. The question of whether the world would be a better place without people with a disability doesn't factor into their decision, and we should not be tempted to blame them for this. Conversely, 
in their individual choices, they seem to feel the influence of a social tendency to equate responsible parenthood with participation in screening and opting for termination after a prenatal diagnosis. Social imaging about disabilities can certainly lead to social pressure that limits the freedom of choice of parents. Individual professionals often make a lot of effort to provide accurate and objective information in their counseling and assist parents in their choices. Of course, improvement is always possible and it is a goal we need to strive for. With regard to this project, Fara is especially interested in how to create a social context in which genuine freedom of choice remains safeguarded.' More information on Fara can be found on www.faranet.be. Fara can be contacted by e-mailing silke.brandts@faranet. be as of October 2018. Prior to that date sindy.helsen@faranet.be can be contacted, as Silke is on maternity leave.

Grip vzw: GRIP (Equal Rights for Each Person with a Disability) is a Flemish civil rights organization for people with disabilities. Patrick Vandelanotte has described Grip's position with respect to our proposal as follows: 'Grip's goal is to achieve equal rights and opportunities for people with a disability. GRIP wishes to influence and stimulate policy and to correctly inform society at large. GRIP supports this challenge to provide future parents, and society at large, with the tools required to make a conscious and well-informed decision on the outcome of prenatal diagnosis without passing judgement. Raising awareness is one of our major objectives. In 2016 GRIP released a reflection about the influence of disability vision on the treatment of ethical questions. One of the proposals of GRIP was to create a framework for hospitals, genetic centers and services about the guidance and support for parents.' More information on Grip can be found on www.gripvzw.be. Grip can be contacted by e-mailing patrick.vandelanotte@gripvzw.be.

Konekt vzw: Konekt is an organization that aims to strengthen people with a disability and their network. Konekt has formulated its position with respect to this project as follows: 'We are curious about and fear for the effects of a society where striving for normality will become stronger and where more and more people will fail to meet the requirements of normality that we impose on others and ourselves. Providing "neutral" information in the context of prenatal screening to us seems as impossible as it is necessary. We have a natural interest for the impossible, so do keep us posted!' More information on Konekt can be found on www.konekt.be. Konekt can be contacted by e-mailing koen.deweer@konekt.be.

Inclusie Vlaanderen: Inclusie Vlaanderen is focused on providing support to people with an intellectual disability. They emphasize the long way that society has come in the manner in which people with a disability are treated (from exclusion over segregation to participation), but indicate where there is room for improvement. They take it to heart to show the value of people with an intellectual disability, and underline their right to equal treatment in society. More information on Inclusie Vlaanderen can be found on www.inclusievlaanderen.be. Inclusie Vlaanderen can be contacted by e-mailing bernadette.rutjes@inclusievlaandren.be.

Gezin en Handicap: The baseline position of Gezin en Handicap vzw, a member of the KVG group (Katholieke Vereniging Gehandicapten) is that parents who can share their own experiences with others will feel stronger and empowered. They organize meetings where information is provided and experiences are shared; they have a documentation center containing more than 4000 books, papers, journals and DVDs on handicaps in general, they provide advice to organizations and generally defend the interest of people with disabilities in a number of advisory boards. When asked to describe their own position as stakeholder to this project, they list the following: 'We could help organize information sessions. In 2015 we have already organized an information session on prenatal counseling for future parents. We mainly focused on ways to ensure a valuable process for parents facing a tough decision. Most participants, however, where future midwifes, future nurses and future social workers. It proved quite hard to reach the parents themselves. We can additionally also help by publishing an article in Handiscoop, our journal.' More information on Gezin en Handicap can be found on www.gezinenhandicap.be. Gezin en Handicap can be contacted by e-mailing lief.vanbael@kvg.be.

RIZIV: The Belgian Government for Health Insurance (Rijksinstituut Voor Ziekte- en Invaliditeitsverzekering, RIZIV) is the organization that is responsible for advice on the (conditions for) refunding medical tests and treatments, including prenatal screening. We have contacted Dr. Ri De Ridder (ri.deridder@riziv.fgov.be) on the matter. Although RIZIV is intrinsically interested in the matter, the organization would currently rather not be involved as stakeholder 
for the project, as this proposal was drafted in a delicate period concerning the decision-making process of refunding the NIPT (see above).

\section{Acknowledgements}

Special thanks go to Professor De Dijn (KU Leuven) and Doctor Kasper Raus (UGent) for their useful comments on earlier versions of this proposal.

\section{Notes}

1 See http://www.downsyndroom.eu/nieuws/over-de-nipt-en-informatie for the vision of Downsyndroom Vlaanderen and an overview of media coverage in the immediate aftermath of the prime minister's decision. 


\section{Supplement 2: Assumptions in the Original Challenge}

This document lists several assumptions in the original challenge, or assumptions that are relevant for our project. These assumptions are divided into six categories, plus we include a seventh paragraph with several assumptions that are also relevant for our research but that are not included in the original document. This was an assignment in an early stage of our project. Therefore, each assumption is accompanied by a preliminary analysis of it, aiming for possible angles for our project and further research.

\section{ASSUMPTIONS CONCERNING PEOPLE WITH DOWN SYNDROME}

The first assumption is the following: 'People with Down syndrome are people.' Who decides the standard for personhood? Should capabilities and functioning have a role to play in this? A capabilities approach is philosophically weak; why should capabilities take precedent in defining personhood? The capability standard in defining personhood is a normative standard we can attack.

Secondly, it is often assumed that people with Down syndrome are happy. This is true according to a qualitative study (Alderson 2001), in which the author examined the lives of several people with Down syndrome. However, the author expressed some reservations regarding the methodology used: it is possible that the participants that are chosen for such studies are more high-functioning and therefore happier. So, we cannot simply assume that Down syndrome comes with happiness. Also, it is common knowledge that measuring happiness is very hard. So, a conclusion may be that studies on the happiness of people with Down syndrome are not very reliable. However, when it comes to people with Down, we can learn from what they tell us. Qualitative research also shows that they can articulate whether they are happy or sad and point out the things in their lives they are happy or unhappy about. They describe hopes, dreams, aspirations as well as difficulties and things they would like to be different in the world.

Another assumption states that people with a disability have a valuable position in society that gives them the 'right to live'. However, why should there be a standard of value or contribution to society in order to obtain that right? A lot of literature looks at whether people with Down syndrome can indeed work and fulfil basic contributions to society in capitalistic terms, but we must ask why this is a requirement at all.

Also, the challenge states that 'Schooling and care for people with Down syndrome still (especially in the later years of life) typically adopts the form of segregation rather than of participation or inclusion'. This seems to assume that segregation in schooling is a bad thing. However, this is a controversial claim, and disability activists themselves are not in full agreement. On the one hand, inclusion suggests equal opportunity for participation. On the other hand, segregation sometimes is more conducive to providing environments for developmentally disabled individuals to receive proper and individualized support, as opposed to being inadequately included in mainstream settings which may not be adequately supportive.

\section{ASSUMPTIONS WITH REGARD TO PARENTS WHO HAVE A CHILD WITH DOWN SYNDROME}

In the document, it seems to be an assumption that parents of a child with Down syndrome see something good when they look at their children. 'When we look at our children, we see people. We see people with hopes and dreams, fears and desires, hands, fingers, toes, favourite food, bath time rituals, bubbles and images of the life we share. ${ }^{1}$ However, it is hard to generalize the viewpoints of parents like that. It may be possible that not all parents view their children like this.

A second assumption can be formulated as following: 'Having a child with Down syndrome does not necessarily cause more suffering than not having it.' This, of course, depends on a comparison of the 'suffering' of having a child with Down syndrome on the one hand with the 'suffering' of not having the child on the other hand. This comparison 
can never be made, and it surely cannot be generalized. However, it is worth investigating the risks of 'suffering' in both cases - keeping in mind that risks are risks, and not harm.

Thirdly, the challenge states the following: 'Down syndrome is one of the most traceable conditions, and hence the first to be subject to this type of large-scale prenatal screening, but it is on average definitely not the most life-shattering condition one can be faced with in terms of quality of life.'2 The truth of this assumption depends, firstly, on your definition of 'life-shattering'; is this meant on a financial, medial, social, emotional or psychological level? Thereby, Down syndrome comes with higher risks of certain disabilities such as autism and Syndrome of West. In severe conditions it might be 'life-shattering', given certain possible definitions of the term. Overall, it might be true that Down syndrome is not the most life-shattering condition; but there are certainly exceptions to the rule.

\section{ASSUMPTIONS CONCERNING SOCIETY AND TAX PAYERS}

Firstly, it is assumed that society sees Down syndrome as something bad, due to medical complications. Indeed, when we look at the literature about the medical, psychological, nursing and ethical aspects of Down syndrome, it has negative referrals such as 'not treatable', 'the most common form of severe mental retardation' linked to 'precocious dementia', associated by mid-adulthood with high levels of (frequently undiagnosed) severe sight and hearing loss, heart and lung disease (often following untreated infections and heart defects), loss of cognitive abilities, epilepsy, serious behavioral problems and 'poor communication or confusion due to Alzheimer disease'. Some pediatric texts mention Down syndrome only with reference to prenatal screening or emphasize severe pathology as if everyone with Down's is very adversely affected. Psychometric research often concentrates on negative issues, such as anxiety, depression, stress and blame, thus tending to present negative reports about Down syndrome. The many surveys of raised anxiety among pregnant women during screening implicitly reinforce assumptions that Down syndrome is something to be very anxious about (Alderson 2001).

Secondly, the challenge suggests that society will hold it against people who (consciously) decide to have a baby with Down syndrome that they cost taxpayers money, or to blame them for high tax costs when parents refuse prenatal testing. These are assumptions that still need more investigation.

Thirdly, the challenges pose the following question: 'Using a raw economy-driven formulation, what is more expensive: providing the correct type of life-long support for people with Down syndrome, or refunding the NIPT to all future parents in the presupposition that the default choice following a positive diagnosis is termination (and hence not having to foot the bill as society)?' Prenatal medical prevention is the logical solution to non-treatable genetic/biological causes of suffering, whereas social/emotional suffering is resolved and prevented by changes in social attitudes and structures toward making societies more inclusive, reforms which are undermined by national prenatal screening programs. Prenatal screening is an effort to reduce the 'costs of life-long care'; however, it may propagate attitudes which restrict independence and employment opportunities of people with Down syndrome (Alderson 2001). For years now, there has been no money from Riziv for refunding speech therapy for children with an IQ lower than 85, for refunding multidisciplinary consultations, for refunding behavioral therapists, or for the expansion of rehabilitation centers. All this support is very valuable for children with Down syndrome and often highly necessary. But suddenly 15 million euros is available for refunding a prenatal screening test for Down syndrome. With this decision, the government seems to give a clear message: 'If you really want a child with Down syndrome, go ahead, but you'll have to manage everything by yourself.' If the government does not provide an equal alternative, it pushes people in the direction of termination. Having a child with Down syndrome might become a possibility only for the rich. So this assumption may turn out to be true.

\section{ASSUMPTIONS CONCERNING THE CHOICE FOR TERMINATION OF THE PREGNANCY OR NOT}

There are several assumptions concerning the question whether we can make a real choice or not. Some examples of possible assumptions are the following: 'Parents choose termination of their child with Down syndrome under pressure of society's desire for perfection'; 'Parents have a right to choose under all circumstances whether or not 
to have a child'; 'Parents can make that choice, because they have "free will"; 'Parents are able to come to a unified choice' and 'Society seems to be evolving to a point where screening is a given rather than a choice'.

The problem of free will itself is already an issue, since nowadays a good section of both neurologists and philosophers have cast serious doubt on the ability of free will to exist. Nonetheless, we must argue that a certain assumption of free will should be made. We are trying to find a method of counseling people on screening for Down syndrome without directing them toward a certain decision. If any method is to be found that entails actual counseling, it must necessarily assume that people have autonomy in making that decision, which means that one must allow for the assumption that they have an autonomous will that can direct itself toward a choice. To challenge this means either to deny the existence of free will as a political necessity, in which case they should not be consulted at all, a mere governmental directive being sufficient, or to deny people autonomous choice up to a certain point. In this last case, which coincides with the second assumption ('Parents have a right to choose under all circumstances whether to have a child or not'), one is dealing with absolutes. The options are, as far as we can tell, fivefold (although more may be thought of):

- The child can be seen as sacred from the beginning, even if it has a condition.

- The child may live if it can live a life in which it will not wish to die by default.

- The transhumanist/eugenic argument, namely that it is incumbent upon society to ameliorate the genetic structure of its citizens or to eliminate pathological elements from the genetic inheritance. Especially now that technology starts to allow for this. The absolute here is that there is no inherent sacredness tied to genetic essence.

- That only those conditions should be kept which either allow for a positive contribution to society, like with certain forms of society, or are unlikely to put an undue burden on society. The absolute being that society should only bring about things to its immediate benefit and has a right to cancel out anything it can that goes against that maxim.

- That society has a duty to minimize the suffering of its citizens, including both children who, if born, would be faced with an enormous disadvantage and parents who are faced with the task of bringing up a child in this situation.

This does not, of course, describe the full scope of the issue, but it suffices for our current purposes. The maxims here described all provide grounds to limit the choice of the parents to give birth to the child or not. And here, at least, decisions must to be made by us and by society at large.

On what basis should parents make their choice? This expresses the worry in the assumption that parents choose for the termination of their child with Down syndrome under pressure of society's desire for perfection. The decision may not be motivated through a healthy philosophical position, but through a rather pathological desire engendered through the culture at large. Should we make people aware of this and, if so, how?

In the decision process, several important considerations must be taken into account. Firstly, it is far from obvious that both parents will come to the same conclusion. This is something that must be taken into account. Also, there is the question of initiating this counseling before or after screening. If it is done after screening, it is debatable whether enough time can be taken to reach a decision. Proper counseling before screening, however, would entail a huge effort, since every pregnancy would entail counseling. Also, in this stage, people may not yet be ready to be confronted with this issue.

Questions concerning free will pose further questions, for example whether genetic screening should be made available to all and what the influence of the government refunding the NIPT test means as imperative to avoid 'abnormal' children. These are questions that would also need further investigation.

\section{ASSUMPTIONS CONCERNING NON-DIRECTIVE COMMUNICATION}

The first assumption here is the following: 'There is such a thing as non-directive communication.' This is a very controversial assumption, with opposite opinions from different perspectives. Most people in the field of communication 
seem to think that it is nearly impossible to really be non-directive while communicating (Clarke 1991, Pennacchini \& Pensieri 2011). Everyone has their own frame of reference built up through life and when we communicate, our own reference will influence what we say and even why we say things. Also, even with the communication of only facts, there will be a nonverbal component: it is hard to hide body language, and this may also show one's feelings about the topic. The nonverbal component is at least as important as the verbal component in communication (Pennacchini \& Pensieri 2011). On the other hand, other people say: 'Let's communicate only in facts and it will be non-directive anyhow.' This is of course not necessarily true: a selection of the facts to be disclosed must be made. Moreover, it has turned out that giving out merely facts will lead to less understanding of the topic. People seem to understand and remember more of the given information when this information is put into perspective and made more practical (Pennacchini \& Pensieri 2011). But of course, when we do this the communication will become more and more directive. A study shows that the great majority of women are being influenced by health professionals in deciding whether or not to continue with an affected pregnancy (Marteau \& Dormandy, 2001). There is also a study that shows that parents are more likely to terminate pregnancies affected by a sex chromosome anomaly when counseled by an obstetrician than by a geneticist or a specialist pediatrician (Marteau et al. 2002). Another study shows that information provided on conditions such as Down syndrome is generally more negative when it is given to those considering prenatal testing than to those considering testing at other times or to parents who have already received a positive test result (Marteau \& Dormandy 2001). This shows that our communication is influenced not only by our own frame of reference, but also by the frame of reference of the people we are talking to.

'The medical practice is the location where such communication should be provided.' This is a second assumption concerning non-directive communication that is important in our research. Ever since prenatal testing has been offered in medical practice, it has seemed to be most logical that communication about it is also provided here. After all, so-called informed consent is needed for every medical act. This means that people should have been given sufficient information by the doctor about the procedure itself and the reasons for it, so that people can make a conscious decision on the matter. Since this principle is there by law, it is mandatory that such communication happens in medical practice. Moreover, information collected in medical practice is seen as reliable: it is often taken seriously by the population. However, one can argue that the government should select and organize the information that is provided, based on the view that prenatal screening is provided as some kind of public health issue. Also, when there are unexpected results or when a certain condition such as Down syndrome is diagnosed, it is argued that the communication should not be done merely by health professionals, but also by professionals in counseling.

Thirdly, a possible assumption is that 'screening for Down syndrome is merely the beginning of a general societal tendency to screen for conditions'. To a great extent, the NIPT test is developed to screen for Down syndrome and other trisomies (trisomy 13 and 18). Now that a way to analyse the DNA of the fetus without any risk for the fetus has been found, it is very likely that researchers will search for other genetic defects such as mendelian deviations, and in the further future even multifactorial conditions. Right now, the NIPT can screen for Down syndrome, fragile $\mathrm{X}$-syndrome, SMA, cystic fibrosis and Edwards' syndrome, and when testing is done after 15 weeks gestation even for neural tube defects and abdominal wall defects. Screening increases, both in the number of tests taken and in the number of conditions that can be screened for (this is an insight acquired in a meeting with Prof. Cassiman). Incentives for this come from the parent(s) who want to be prepared, from the fact that it is possible to do so, and there may also be an important role of commercial companies that find a new way of making money with the offering of these kinds of possibilities to screen for more conditions.

Fourthly, we should investigate whether the claim that centers for human genetics typically make efforts to provide non-directive counseling holds. This assumption seems to be true: indeed it seems clear that centers for human genetics typically have much better knowledge about the conditions which we screen for such as Down syndrome in comparison with GPs or gynecologists. Therefore, these centers can provide more information and details about the conditions and the risks of repetition in a next pregnancy (this is an insight we acquired through our meeting with Prof. Cassiman). Generally, in these centers, more time is provided per consultation to give a detailed explanation than in consultation at the gynecologist's office. In the limited time gynecologists have available per consultation, 
prenatal screening is only one of the many topics that must be discussed. So, centers for human genetics probably can provide better counseling, but future parents are usually sent there only when there already is a suspicion or confirmation of a condition.

Lastly, it must be investigated whether communication in the gynecologist's offices is indeed, as suggested in the original challenge, too idiosyncratically tied to specific profiles. Unfortunately, there is little data revealing how genetic counselors communicate about disabilities in the context of prenatal setting. A study on topic reveals that most counselors (95\%) focus on the physical aspects of disability, while fewer (27\%) discuss the social aspects. In addition, few genetic counselors (38\%) asked patients about personal experiences with disability. When discussing possibilities, most genetic counselors mention termination $(86 \%)$ while fewer mention the continuation of the pregnancy $(37 \%)$ or adoption $(13 \%)$. Only half of the genetic counselors ask if the future mom had thought about how she might use the results of prenatal screening (Farrelly et al 2011). In another study by Leonard et al., parents of families containing children with cystic fibrosis, phenylketonuria, and Down syndrome were asked questions designed to discover their understanding of the genetic counseling that they received. Although all the families had been counseled, about 1/2 had a good grasp of the information given, 1/4 gained something, and $1 / 4$ learned very little. This variation is probably due to differences in the contexts in which the counseling was provided, including variable skills of the physicians who provided it, but it is also associated with the knowledge of biology and the perception of the usefulness of the counseling that the parents brought to it (Leonard et al. 1972). There is also a study available that indicates that gynecologists in general have a lack of interdisciplinary knowledge to offer the right counseling to pregnant women (Harris et al. 2005). Another explanation for the inadequate counseling could be that gynecologists spend less time in providing information to women with an a priori low risk in comparison with women with a high risk.

\section{ASSUMPTIONS CONCERNING (SOCIAL) MEDIA}

There are lots of assumptions visible about the (social) media, such as the following: '(Social) media have an important role in the dissemination of stereotypes and public opinion on Down syndrome', and 'Risk and harm are confused in the public debate on Down syndrome.' This paragraph explores the role of social media in the perception of Down syndrome.

If we look at social media, we observe that they have become a platform for interaction, discussion, the sharing and consuming of information and the production of political information. This way of exchanging information has an impact on political participation, perceptions of opinion leadership, attempts at political persuasion (Brian 2017).

Looking at previous studies, we observe that media consumption affects social interactions. Bryant \& Zillmann stated that media effects are social or psychological changes that occur in consumers of media messages because they are exposed to those messages: they process them or even act on them (Bryant \& Zillmann 2009, pp. 9-18).

When we ask ourselves what kind of information we acquire through the media, we find that most of what people know comes to them from the mass media or from other people (Lang \& Lang 1966, p. 466). The mass media force attention to certain issues. They build up public images of political figures, they are constantly presenting objects suggesting what individuals should think about, know about, have feelings about (Lang \& Lang 1966, p. 468). Adapted to our research question, Goethals argues that 'the mass media are a useful source of information about current and historical norms and values, public opinions and attitudes on disability' (Goethals 2017).

There are only a small number of studies that systematically explore the media representations of people with Down syndrome. What these studies show, is that what is depicted in the media is not an exact representation of the realities of disability identities in society (Goethals 2017, p.52). This is also the case on social media. Many initiatives such as T21 Mum Australia have their own Facebook page to connect moms and provide support by the organization of online and real-life events. For the month of October, which is World Down Syndrome Awareness Month, T21 Mum Australia denounced the negative stigma associated with Down syndrome: 'Children with Down syndrome are not lazy, stubborn, and definitely not always happy. Children with Down syndrome don't always like hugs or naturally like 
music. These are all stereotypes associated with the diagnosis. Children with Down syndrome are just children. They are individuals with ranges of abilities, interests and personalities.'

Another aspect that should be taken into consideration when looking at stereotypes is the language used in media content related to Down syndrome. The language used in media can shape our view on people with Down syndrome. Several associations have published a guide to suggest the use of adequate language for Down syndrome-related issues in the media. 'Language choice can empower people' is a statement found in the media guide offered by Down syndrome Victoria in Australia. The guide proposes to 'try not to portray people with a disability as objects of pity or as brave' and comes up with a list of words which are to be favored over misused terms. 'The key consideration is to always put the person first, not the disability.' In Dutch, for example, the correct term is 'iemand met Down syndroom', not 'mongooltje'.

The A\&E reality show Born this way portrays a group of young adults having Down syndrome in their everyday lives in the US. The series also shows their parents and the joys and challenges that they encounter in supporting their children. The channel had a coverage of 81.6 per cent of households in 2015 , so the series had great potential to reach out to a wider public. The image given to the audience is overall very positive, the characters pursue their dreams and careers just like people without Down syndrome. The website of the TV show also provides a language guide and a viewing guide with further information on Down syndrome to encourage discussions at college level as well as for general audiences. Evana Sandusky, who is a language speech therapist for children, mother of a child with Down syndrome and author of The Mighty (a blog on health and parenting issues), complains that people with Down syndrome who appear in the media are certainly not those who struggle the most: 'Support comes from all directions celebrating those with Down syndrome with extra-special talents who seem to meet the world's view of success.'

A study conducted in New Zealand in 2014 on the media portrayal of Down syndrome observed that recent mixed media coverage of the topic is critical, complex and socially inclusive of people with Down syndrome: it seems to be politically correct. Although the quality of life for people with Down syndrome was represented as slightly negative, the study showed no strong directional reporting. Most of the time, articles in New Zealand's media focused on issues of society, government and care rather than genetics, screening and testing (Wardell et. Al 2014, 242-250).

According to Goethals, 'there is a complex relationship between media coverage and the public, the media have a powerful influence on the way "disability" as a phenomenon is perceived and on the process of attitude formation.' Her analysis conducted between January 2003 and December 2012 showed that there is very little coverage on people with disabilities or even a 'total lack of representation in certain media sources' (Goethals 2017).

In any case, media representation is of major importance: Tsfati argues that stigmatization of minority groups in mainstream media makes minority members more likely to feel alienated. (Tsfati 2007, pp. 632-651.)

\section{ASSUMPTIONS THAT ARE MISSING IN THE ORIGINAL CHALLENGE DOCUMENT}

Other assumptions, related topics and research questions that might be worthwhile exploring are for example:

- Are people capable of deciding the criteria for prenatal screening?

- Are parents capable of fully assessing what parenthood is all about, prior to becoming parents?

- Are fetuses people? Do they have rights?

- Is communication about Down syndrome (or generally about the disability you are screening for) more important than communication about screening in general?

- Should society make sure that people with disabilities make up a relevant proportion of society and maintain a certain position within it?

- What role do personal experiences play in the decision-making process, and what role should it play? What roles should personal experience, the media and doctors have within the process?

- Pharmaceutical companies (and other private companies) have their own gain in making the test widely available; is this a good thing? 


\section{Notes}

1 Original challenge document, p. 45.

2 Original challenge document, p. 46.

\section{References}

Alderson, P., 'Down syndrome: cost, quality and value of life'. Soc Sci Med [Internet]. 2001;53(5):627-38. Available from: http://www.sciencedirect.com/science/article/pii/S0277953600003658

Brian E., 'Online Influence? Social Media Use, Opinion Leadership, and Political Persuasion'. International Journal of Public Opinion Research Vol. 29 No. 22017.

Bryant, J., \& Zillmann, D. 2009. 'A retrospective and prospective look at media effects'. In L. R. Nabi, \& M. B. Oliver (Eds.), The sage handbook of media processes and effects, 9-18.

Claire O. Leonard, Gary A. Chase, A. \& Childs, Barton, 1972, 'Genetic Counselling: a Consumer's View', in The New England Journal of Medicine, 287, 433-439.

Clarke, Angus, 1991, 'Is Non-directive Genetic Counselling Possible?'. In The Lancet, 338, 998-1001.

DADA Study Group comprising Marteau, Theresa M, Irma Nippert, Sue Hall (writing committee), Caroline Limbert, Margaret Reid, Martin Bobrow, Alan Cameron, Martina Cornel, Mariet van Diem, Bernd Eiben, Sixto García-Minaur, Janine Goujard, Donna Kirwan, Karen Mclntosh, Peter Soothill, Corien Verschuuren-Bemelmans, Catherine de Vigan, Stephen Walkinshaw, Lenore Abramsky, Frank Louwen, Peter Miny and Jürgen Horst, 2002, 'Outcomes of pregnancies diagnosed with Klinefelter syndrome: the possible influence of health professionals' in Prenatal Diagnosis, 22: 562-566.

Farrelly et al., 2011 'Genetic Counseling for Prenatal Testing: Where is the Discussion About Disability'. In Farrelly, Ellyn, Mildred K. Cho, Lori Erby, Debra Roter, Anabel Stenzel \& Kelly Ormond. 2012. Genetic counseling for prenatal testing: Where is the discussion about disability? Journal of Genetic Counseling 6: 814-824.

Goethals, Tina, 2017, 'Inclusion of persons with disabilities in Flanders. A "participatory" research project on personal narratives, the representation of persons with disabilities in the media and political participation of persons with an intellectual disability' (PhD Thesis).

Harris, Rodney \& Lane, Beverley \& Paris, Hilary \& Williamson, Paula \& Dodge, John \& Moddell, Bernadette \& Ponder, Bruce \& Rodeck, Charles \& Alberman, Eva, 2005, 'National Confidential Enquiry into counselling for genetic disorders by non-geneticists: general recommendations and specific standards for improving care', in An International Journal of Obstetrics and Gynaecology https://doi.org/10.1111/j.1471-0528.1999.tb08364.x.

Lang, Kurt \& Lang, Gladys Engel, 'The Mass Media and Voting'. In Bernard Berelson and Morris Janowitz, eds., Reader in Public Opinion and Communication, 2d ed., New York, Free Press, 1966, p. 466.

Marteau, Theresa M \& Dormancy, Elizabeth, 2001, 'Facilitating Informed Choice in Prenatal Testing: How Well Are We Doing?' In American Journal of Medical Genetics (Semin. Med. Genet.), 106, 185-190.

Pennacchini, M. \& Pensieri, C., 'Is non-directive communication in genetic counseling possible?'. In Clin Ter, 162, $141-144$

Tsfati, Y., 2007. 'Hostile media perceptions, presumed media influence, and minority alienation: The case of Arabs in Israel'. Journal of Communication, 57, 632-651.

Wardell, S. et. al., 2014, 'A qualitative and quantitative analysis of the New Zealand media portrayal of Down syndrome'. Disability and Health Journal 7, 242-250. 


\section{Supplement 3: Website table of content}

This supplement section provides a detailed table of contents for the website downtocounsel.weebly.com which is currently in the making. Each thematic section is associated with questions covering many elements of counseling. One example of such a question is provided for each section in the table of contents.

The answers and information listed in the proposed table of content are of course nonexhaustive. To keep the information up-to-date and as close as possible to our users' needs, we seek to cooperate with medical staff using our website. The information provided on downtocounsel.weebly.com can be completed with the help of users through online feedback, which will be accessible on the website. The form to be used can be found on the last page of this section.

\section{INTRODUCTION}

Medical bias

- How can I provide a transdisciplinary approach to counseling?

\section{SCREENING}

\section{Consequences of NIPT}

- What does the NIPT change regarding the choices that people face?

Medical timeline

- How do I communicate about the medical timeline?

Choosing to screen

- In what way can I present the choice of whether to screen without diminishing either the medical value of screening or the personal free choice of my patient regarding the matter?

Future developments

- What future developments can l expect?

Screening \& free market

- How should I address free market options when my patient brings them up?

\section{THE DECISION-MAKING PROCESS}

Well-informed decision-making

- What makes decision-making so difficult for prospective parents?

- What if counseling from organizations does not help?

- What should parents realistically expect from counseling?

Non-directive counseling and nudging

- Which organizations can I refer to for decisionmaking support after a positive result has been disclosed? 
Stigmas and stereotypes

- What language should be used in talking about Down syndrome in counseling?

Individual factors influencing decisions (age, gender, ethnicity)

- What social factors influence the decisionmaking process?

Post-decision counseling: guilt and other obstacles

- What if parents need help coping with their decision?

\section{LIVING WITH DOWN}

Independent life

- To what extent can people with Down syndrome have an independent existence?

Therapy and support

- What support can be given to people with Down syndrome in the current society in Flanders, and by what organizations?

Everyday life: from kindergarten to professional life

- Can people with Down syndrome go to a normal school?

- What job opportunities are there for people with Down syndrome?

Family life: ASS or pattern-proof? Practical aspects: bathing, cleanliness, food, transport, vacation, life stages (transition to adulthood, growing old with Down)

- What are practical concerns that should be taken into account when you have a child with Down syndrome?

Social aspects (integration)

- What can I do if a child with Down syndrome faces exclusion?

- How far does having a child with Down syndrome affect my own social life?

- What implications does having Down syndrome have for your social life?

Subjective experiences of living with Down syndrome

- What does it mean to have a sibling with Down syndrome?

Financial aspects

- What are the financial implications of living with a child with Down syndrome?

- What financial aid is there currently available in Flanders?

International/historical perception of Down syndrome

- In what aspects does the current situation in Flanders differ from that in other regions or countries with regard to education, job opportunities, financial aid and so on?

- In what aspects does the current situation in Flanders differ from that in the past?

- What organizations strive for progress or emancipation for people with Down syndrome? 


\section{Supplements 4-10: Description of the video and audio fragments}

\section{SUPPLEMENT 4 (VIDEO FRAGMENT 1)}

This supplement concerns a video of a mom of a child with Down syndrome we met. In this video she tells about her experiences during her pregnancy with her child. This video shows that counseling in a non-directive way is extremely important. Negative and discouraging counseling should be avoided. This fragment is an extract from a five-minute interview.

\section{SUPPLEMENT 5 (VIDEO FRAGMENT 2)}

During our one hour talk with Fara, we talked about counseling for prenatal screening. Fara is an organization that counsels women and couples about choices in pregnancy, among which are choices regarding termination of pregnancy in case of a prenatal diagnosis of a fetal condition. This one-minute extract concerns the weight that can be felt by parents either by choosing to terminate or to keep the child and therefore the importance of the decision-making process.

\section{SUPPLEMENT 6 (VIDEO FRAGMENT 3)}

In this extract of a one and a half hour talk with Dr. Raus, he tells us about nudging in healthcare and the importance of how to convey information to parents. Dr. Raus is a bio-ethicist at the University of Ghent.

\section{SUPPLEMENT 7 (VIDEO FRAGMENT 4)}

In this extract you can see two parents with their little daughter, who has Down syndrome. The father tells us what convinced him to make the choice of keeping his daughter. This is an extract of twelve minutes from the talk.

\section{SUPPLEMENT 8 (VIDEO FRAGMENT 5)}

This extract shows the mother of a child with Down syndrome. She tells us about her experience with the doctors after she received the positive NIPT result. This video is an extract of six minutes during the talk.

\section{SUPPLEMENT 9 (AUDIO FRAGMENT 1)}

This audio fragment is from a one-hour meeting with Professor Cassiman, one of our stakeholders. He is a geneticist at the KU Leuven. In this meeting we obtained a lot of information about the genetics of Down syndrome, the details of the NIPT and the counseling performed at the centers for human heredity. This selection of audio fragments of the meeting with Professor Cassiman represents our main insights from the session.

\section{SUPPLEMENT 10 (AUDIO FRAGMENT 2)}

This audio fragment concerns a selection of fragments of a one and a half hour meeting with Prof. De Catte. He is a gynecologist at UZ Leuven and specialized in prenatal screening and diagnosis. Most of all he gave us important insights into the best way to reach a gynecologist and how to present our information to them. This selection of audio fragments of the meeting with Professor De Catte represents our main insights from the session. 


\section{Supplement 11: Actor constellation game}

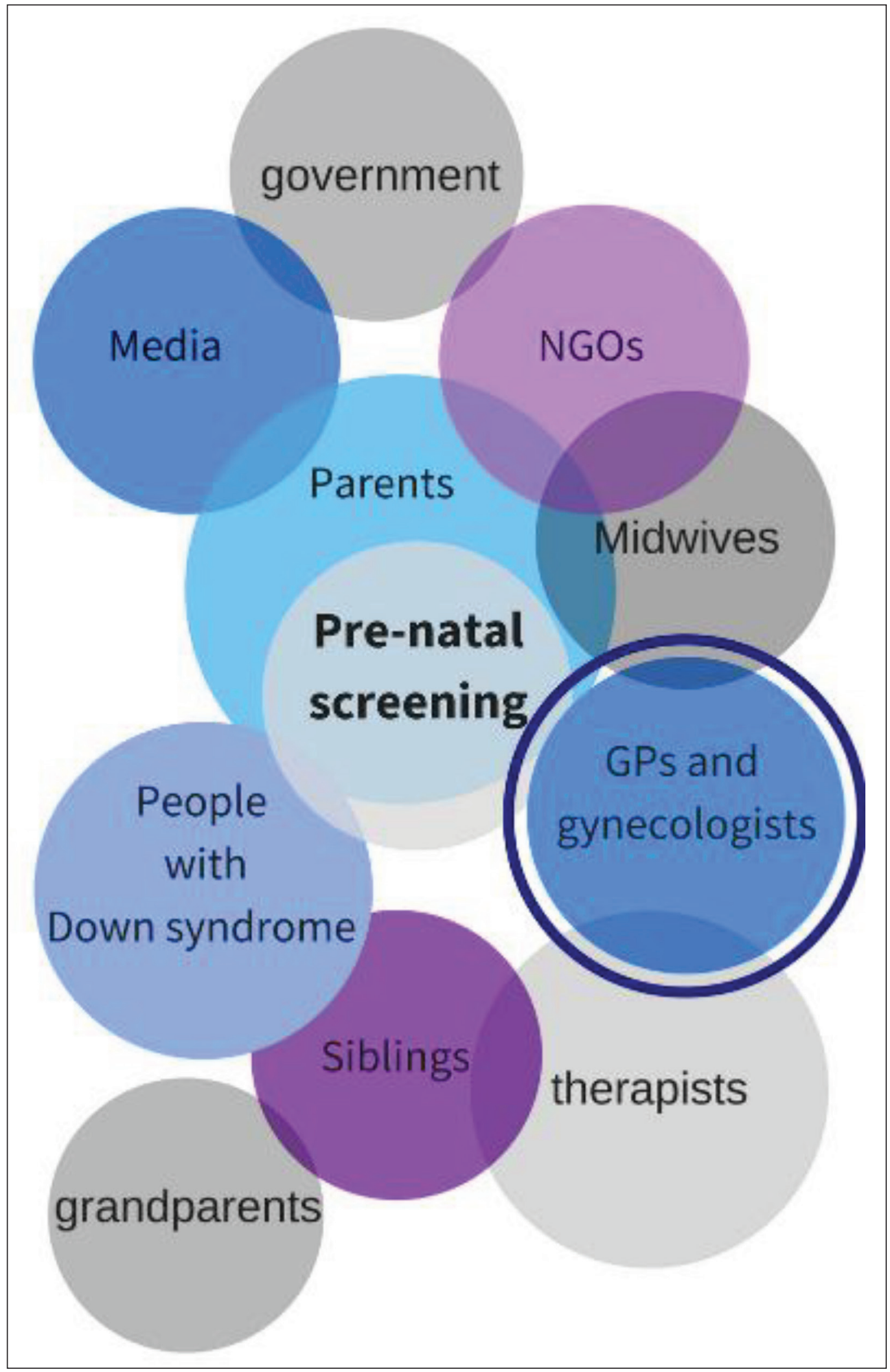




\section{Supplement 12: Facing the Future Symposium Presentation}

Laura Costan, Matthew J. Devine, Maud van Dinther,

Louise Hendrickx, Job Meijer, Nynke van Uffelen, Eline

\section{Non-Directive Counselling in Prenatal screening for Down's Syndrome}

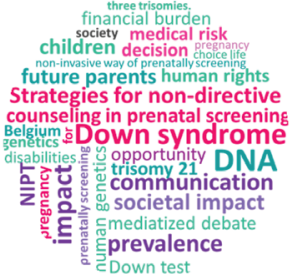

TRANSDISCIPLINARYINSIGHTS 2017 - 2018

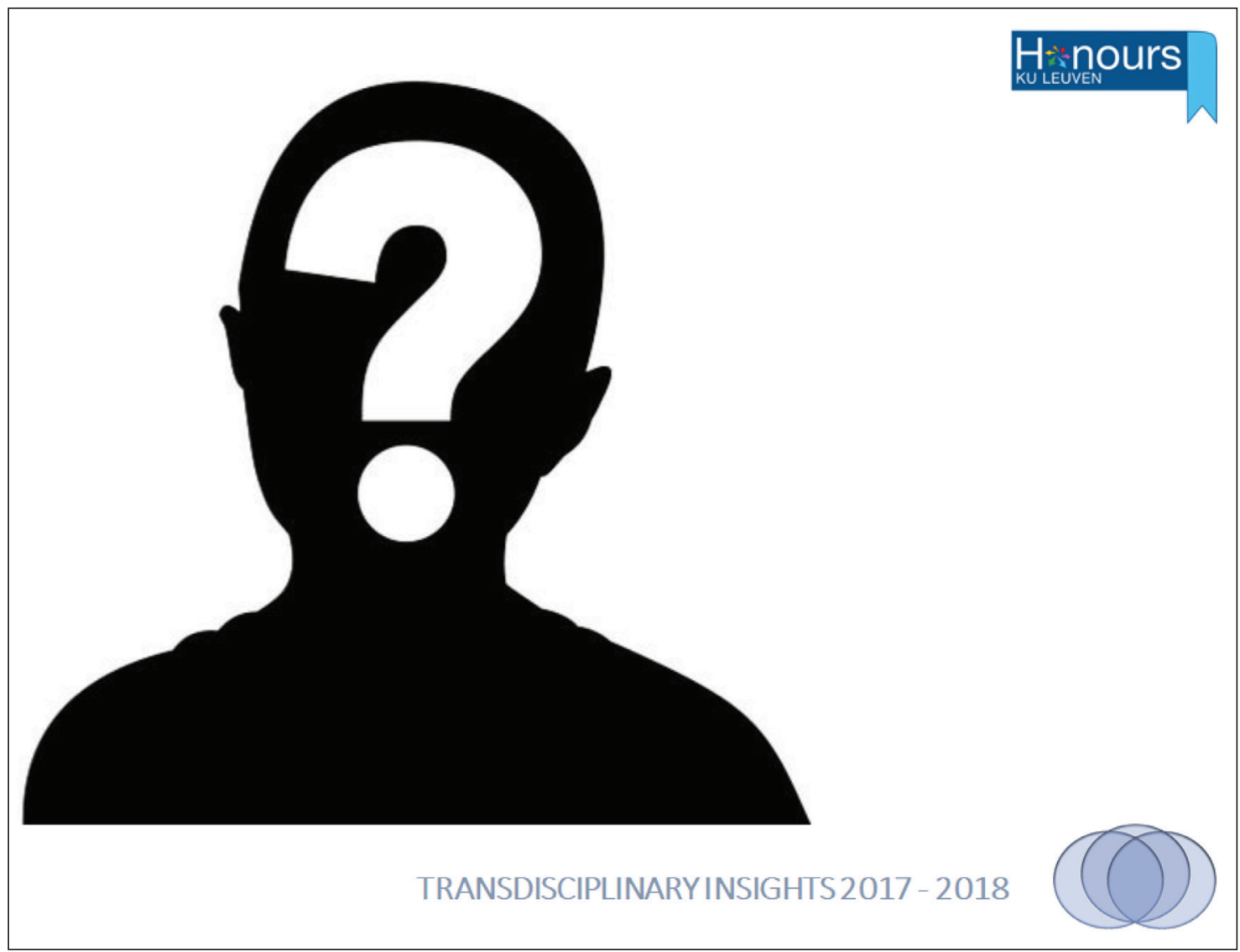



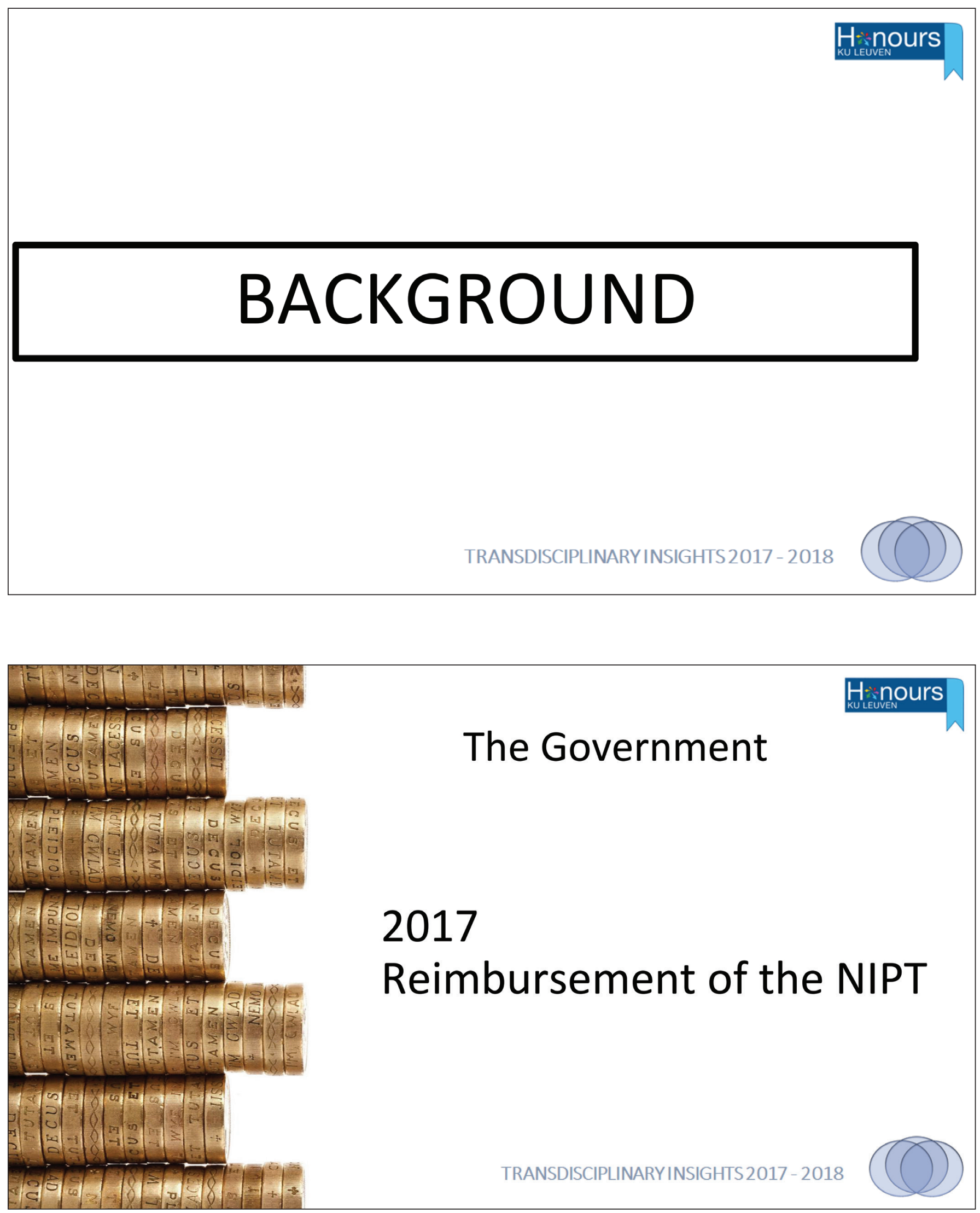


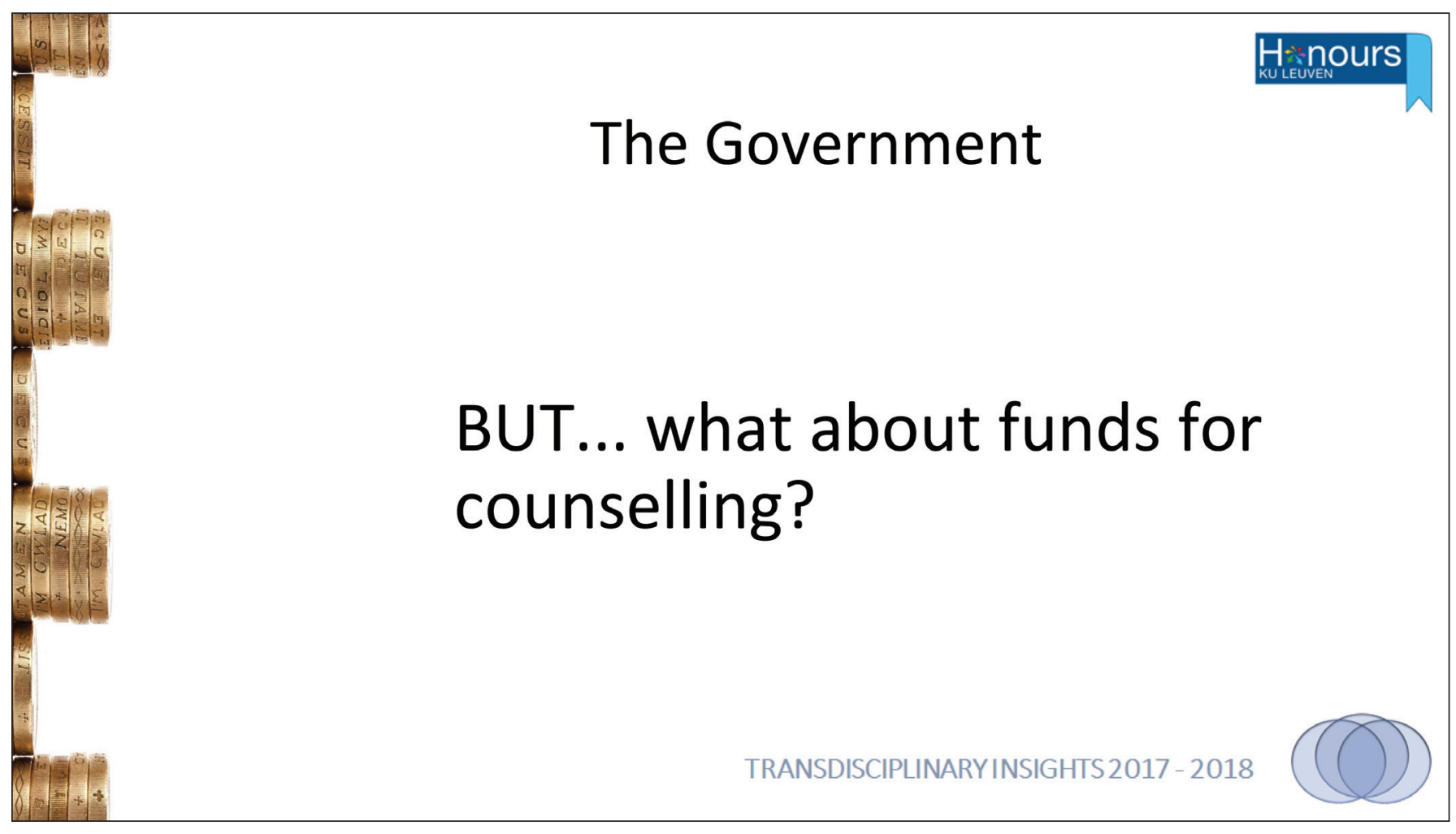

\section{CHALLENGE}



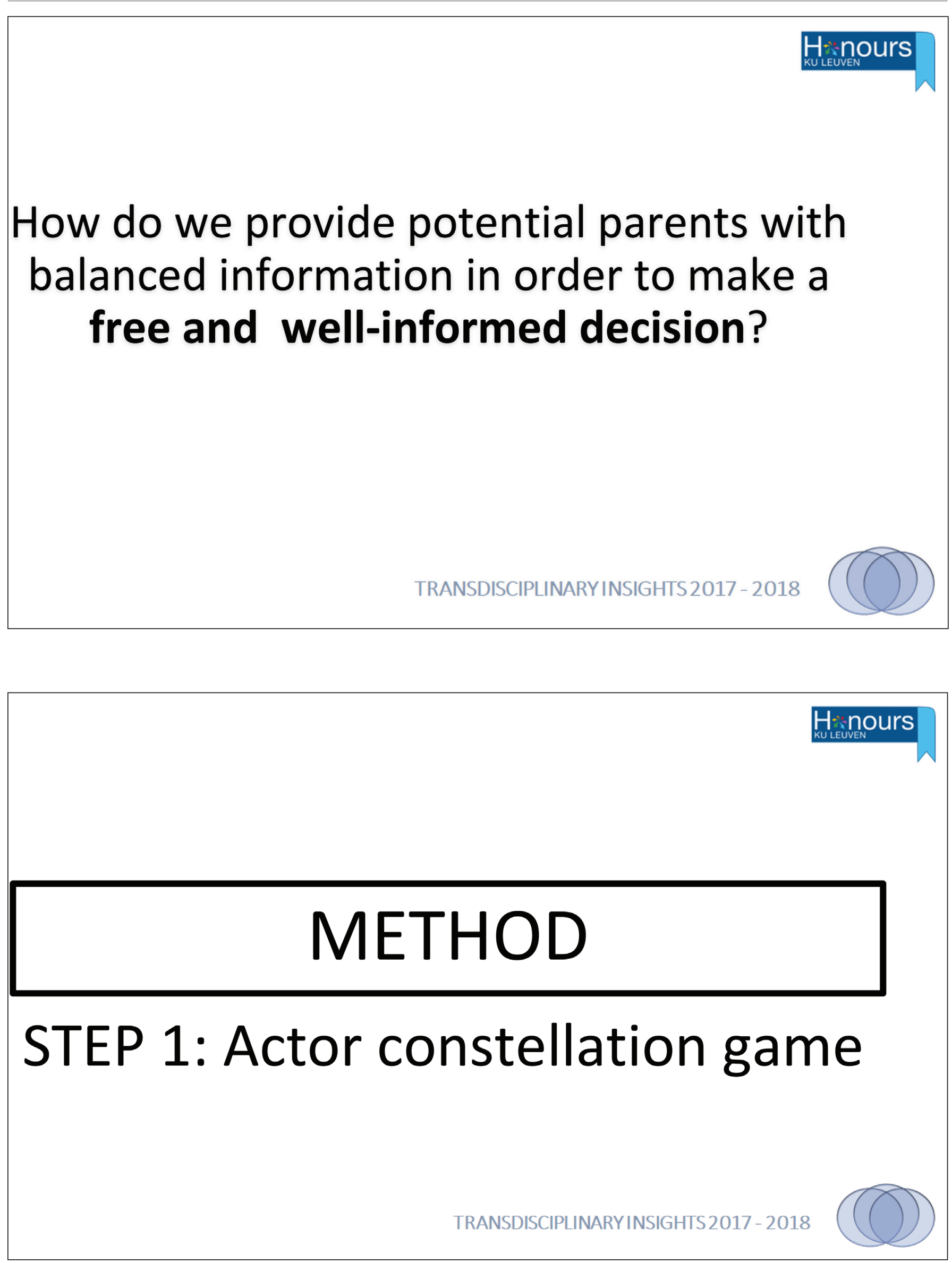


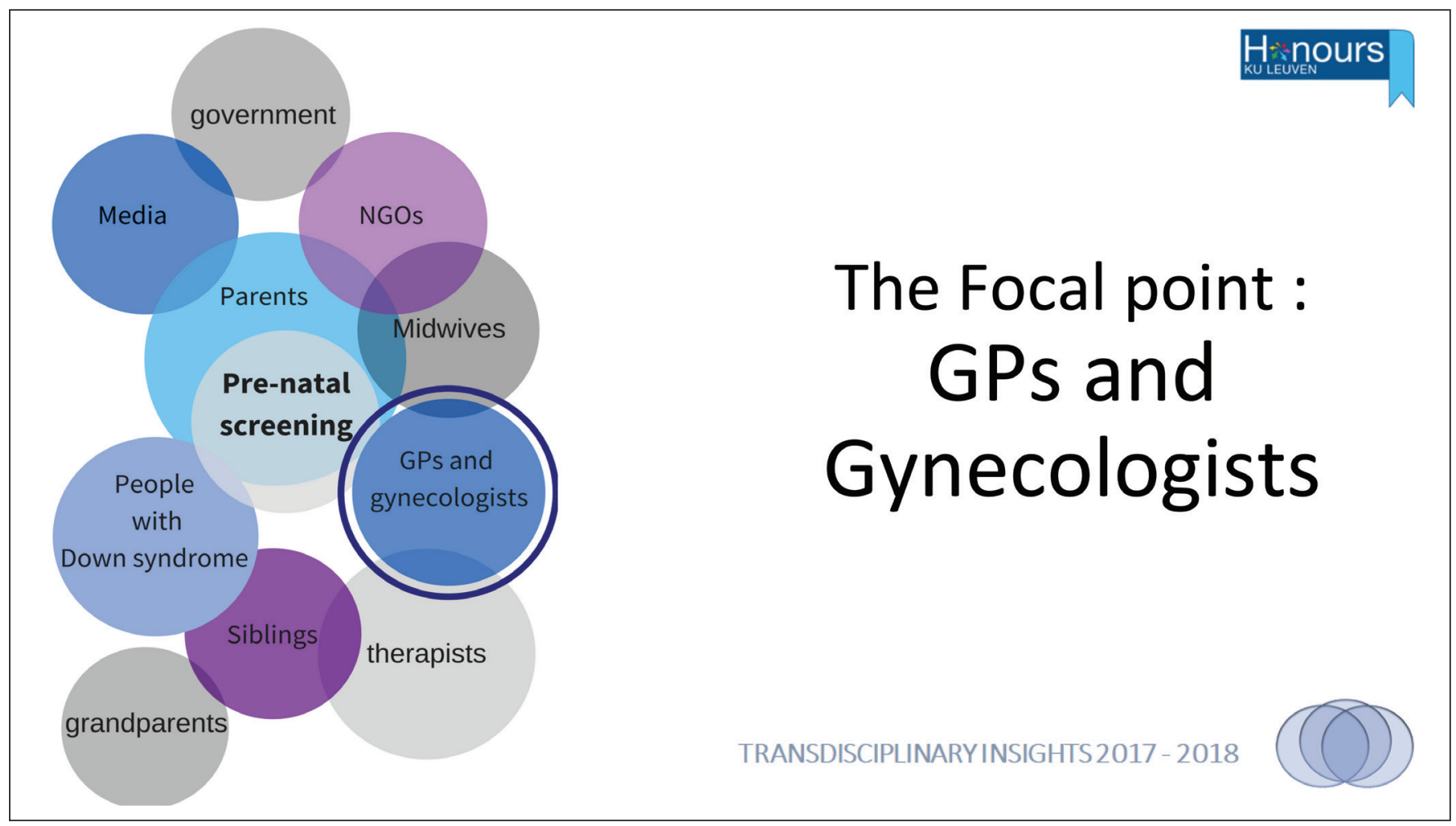

\section{Obstacles}

- Purely medical perspective - need for a transdisciplinary perspective

- Time issues 

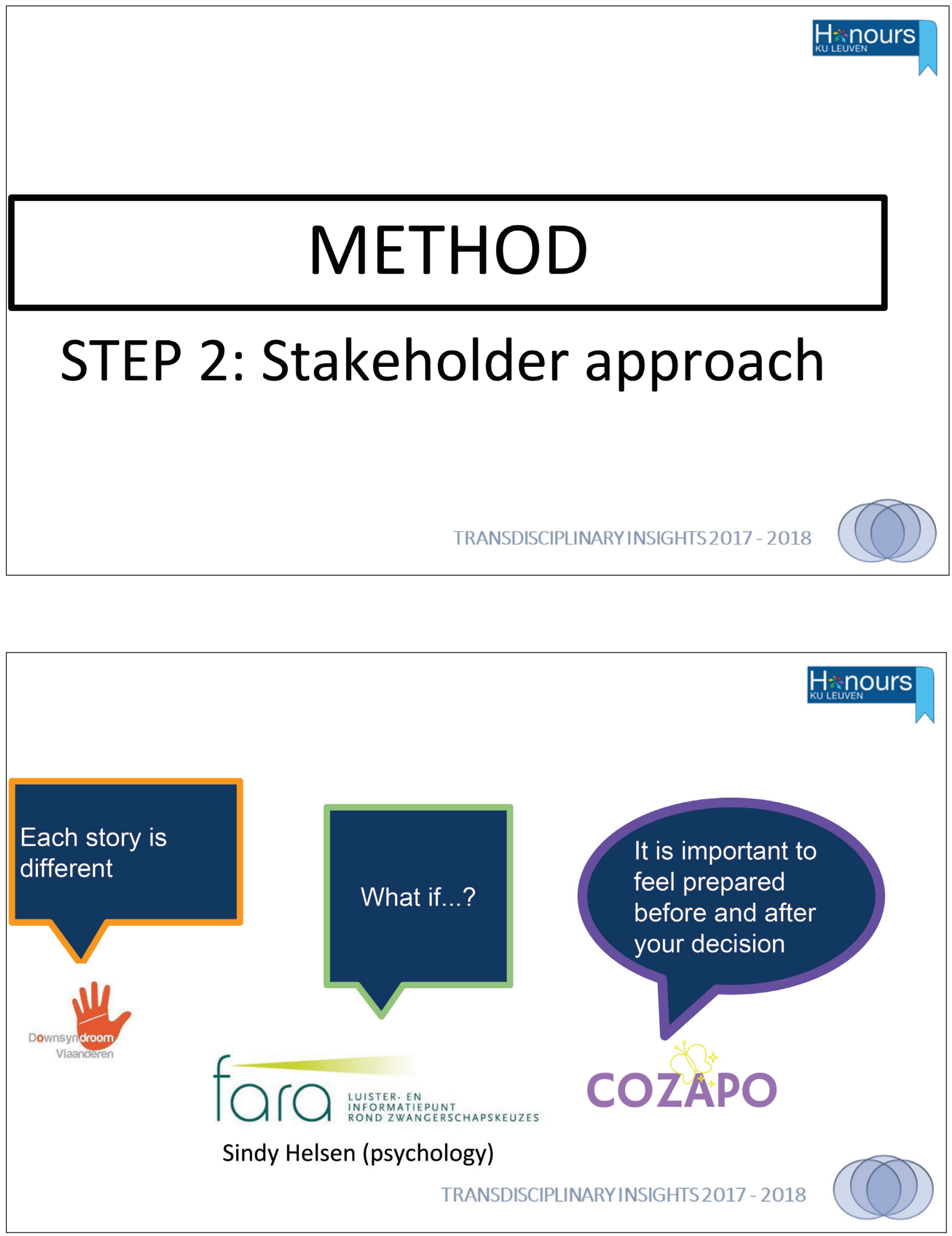

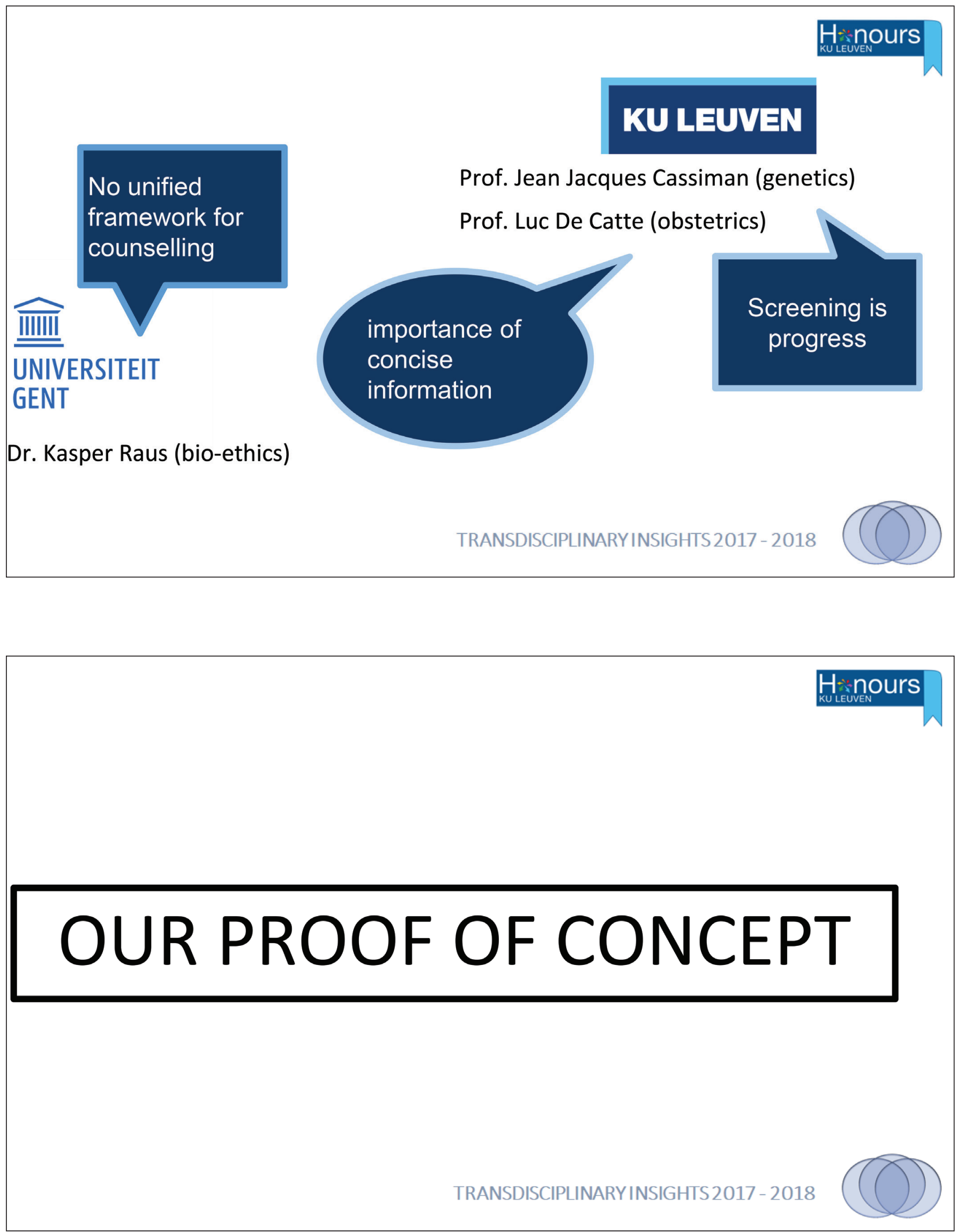


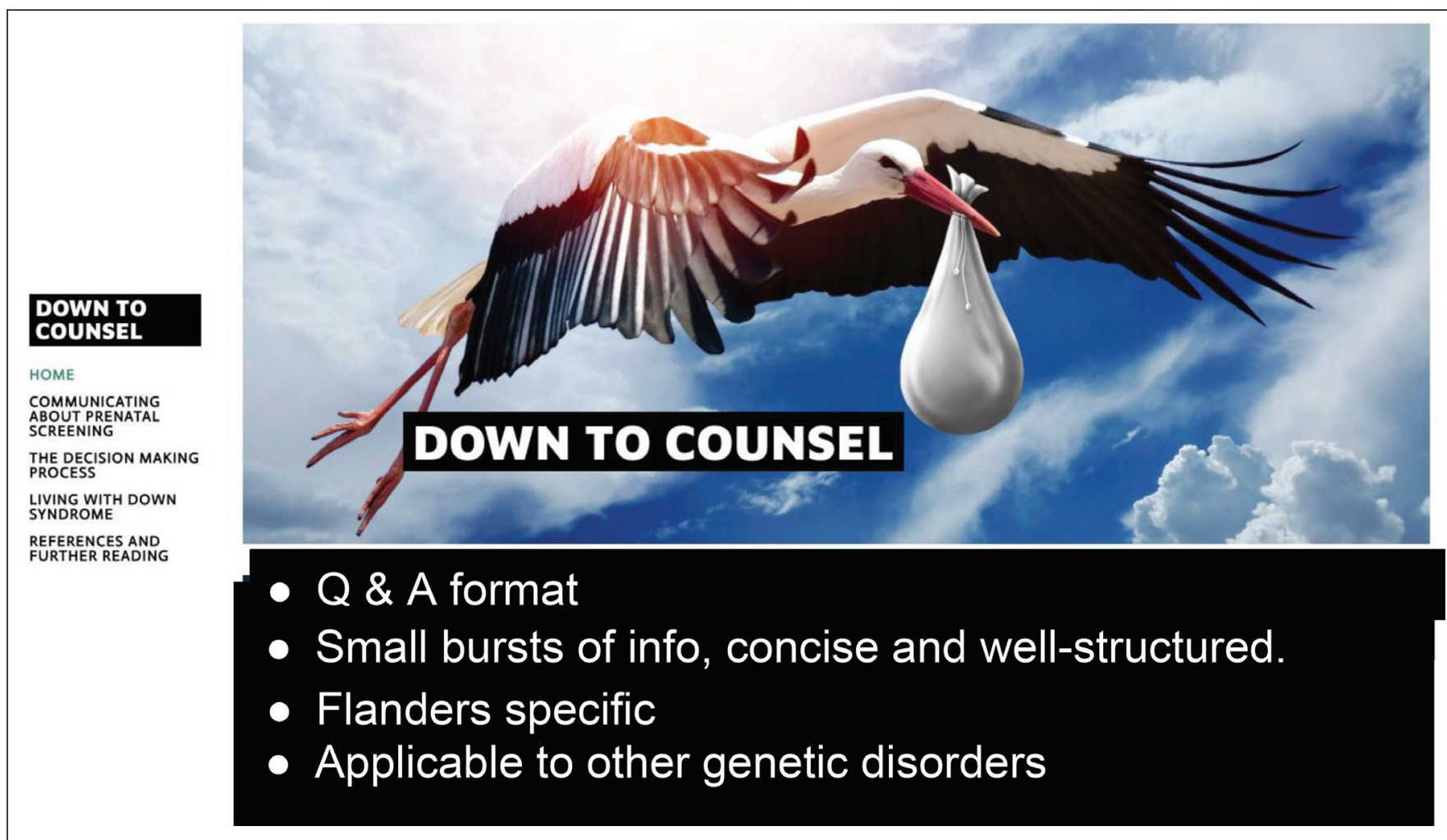

\section{The Content}

\section{Introduction}

1. Communicating about Prenatal Screening

2. The Decision-Making Process

3. Living with Down Syndrome

References and Further Reading

A Feedback/Contact Form 


\section{The Content}

Introduction

1. Communicating about Prenatal Screening

2. The Decision-Making Process

3. Living with Down Syndrome

References and Further Reading

A Feedback/Contact Form

\section{The Content}

Introduction

1. Communicating about Prenatal Screening

2. The Decision-Making Process

\section{Living with Down Syndrome}

References and Further Reading

A Feedback/Contact Form 


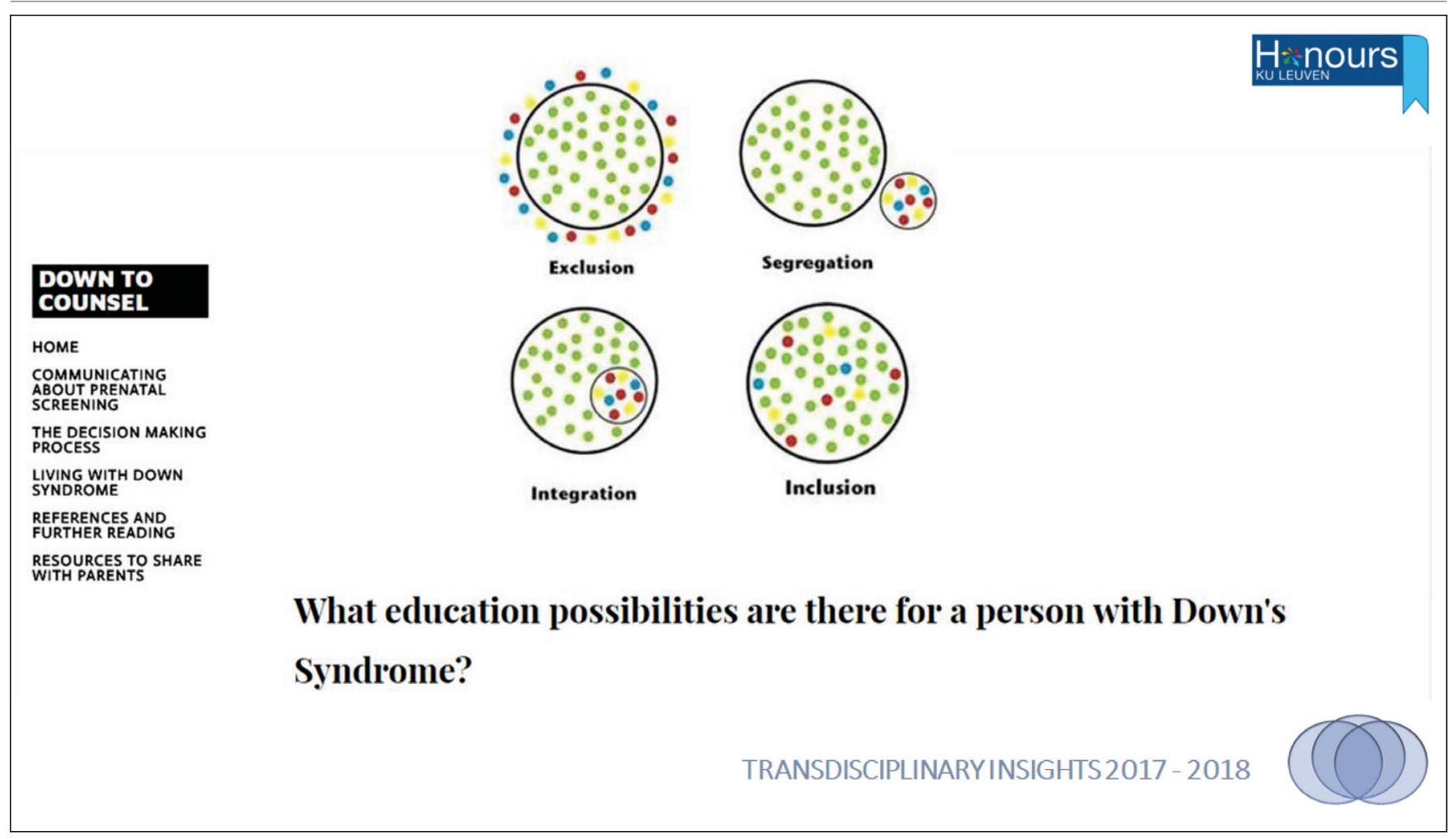

\section{The Content}

Introduction

1. Communicating about Prenatal Screening

2. The Decision-Making Process

3. Living with Down

References and Further Reading

A Feedback/Contact Form 


\section{RESOURCES FOR PARENTS}

\section{DOWN TO \\ COUNSEL}

HOME

COMMUNICATING

ABOUT PRENATAL

SCREENING

Fara: https://www.fara.be/

THE DECISION MAKING

PROCESS

Cozapo: https:/sites.google.com/cozapo.org/welkom/welkom

LIVING WITH DOWN

SYNDROME

REFERENCES AND

FURTHER READING

VVOG: https://www.vvog.be/

Down's Syndroom Vlaanderen: http://downsyndroom.eu/

Inclusie Vlaanderen: www.inclusievlaanderen.be

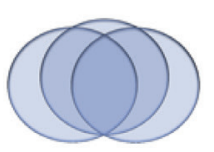

\section{DOWN TO}

HOME

COMMUNICATING ABOUT PRENATAL

SCREENING

THE DECISION MAKING PROCESS

LIVING WITH DOWN

SYNDROME

REFERENCES AND
FURTHER READING
Alderson, Priscilla. "Prenatal Screening, Ethics and Down's Syndrome: A Literature Review." Nursing Ethics 8, no. 4 (2001): $360-374$.

Sheets B., Kathryn et. al. "Practice Guidelines for Communicating a Prenatal or Postnatal Diagnosis of Down Syndrome: Recommendations of the National Society of Genetic Counselors.” Journal of Genetic Counselling 20: 432-441. (2011). DOI $10.1007 / 7 \mathrm{S10897-011-9375-8.}$

Reid, Bernie et. al. "A meta-synthesis of pregnant women's decision-making processes with regard to antenatal screening for Down syndrome". Social Science \& Medicine 69 (2009) 1561-1573.

Vanstone, Meredith, et al. "What Is "NIPT"? Divergent Characterizations of Non-invasive Prenatal Testing Strategies." AJOB Empirical Bioethics, vol. 6, no. 1, 2015, pp. 54-67.

TRANSDISCIPLINARYINSIGHTS2017 - 2018 


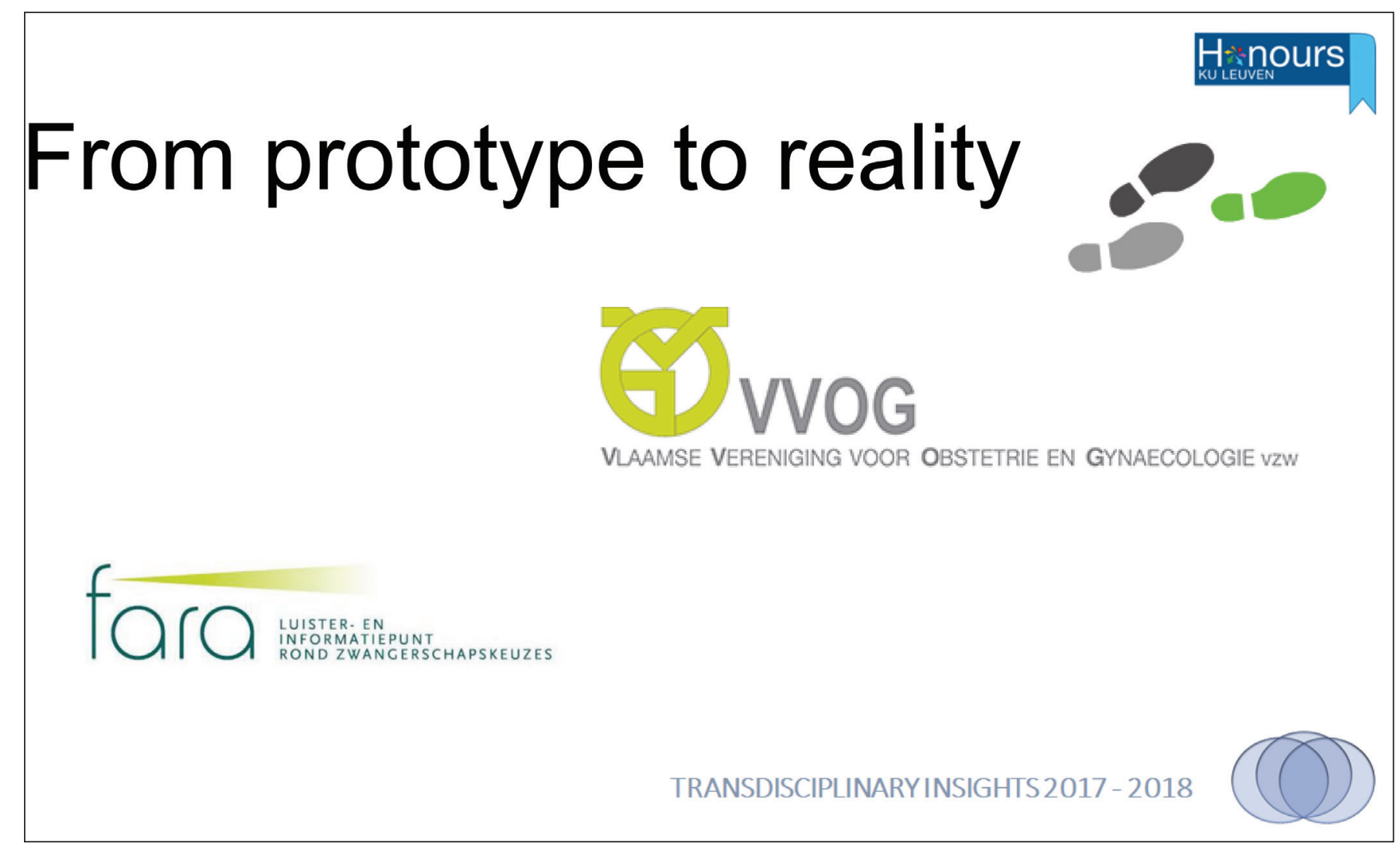



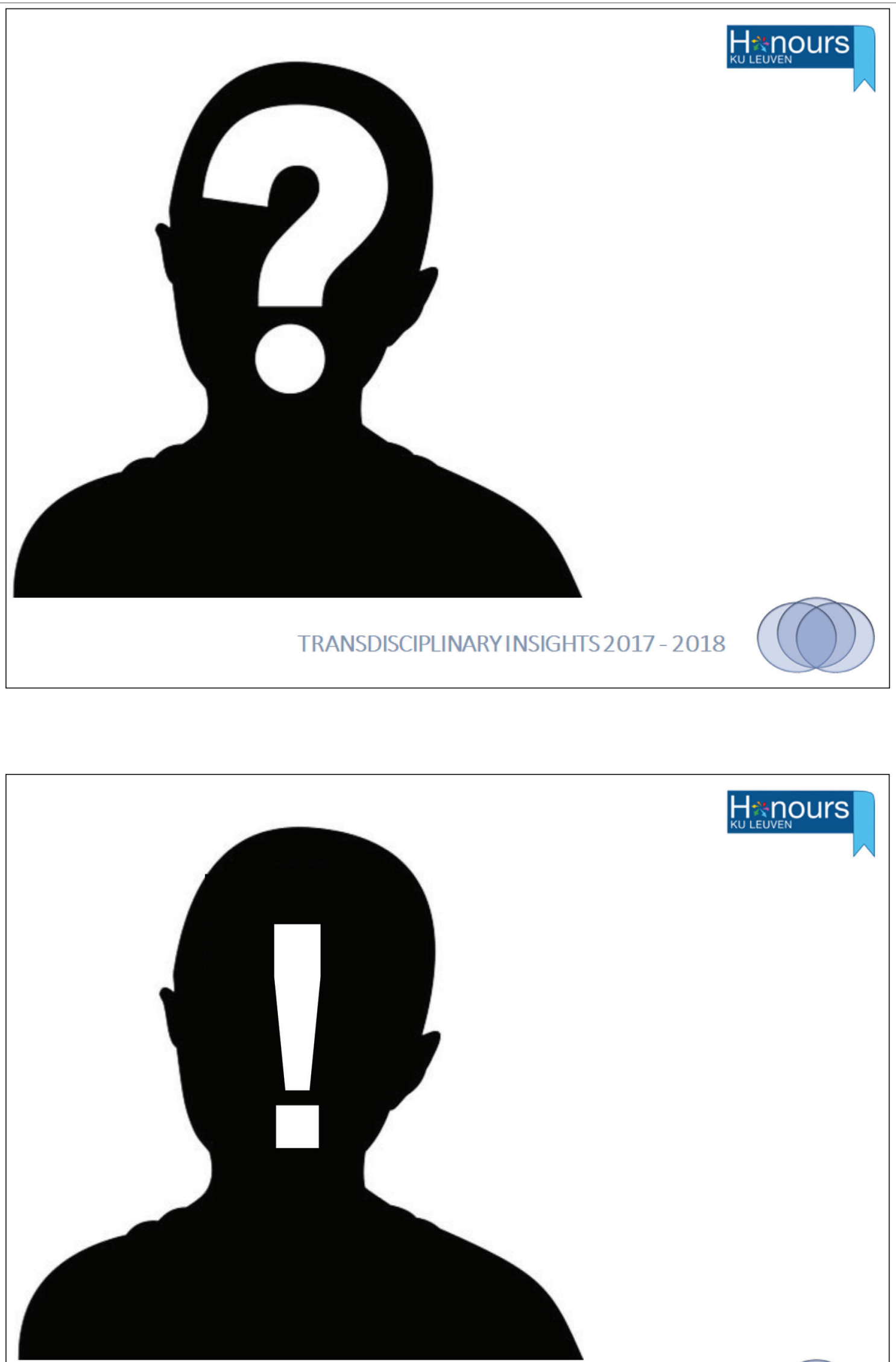

TRANSDISCIPLINARYINSIGHTS2017- 2018

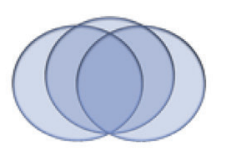

